Strauss, K., \& Parker, S. K., Intervening to enhance proactivity in organizations: Improving the present or changing the future. Journal of Management, 44(3), 1250-1278). Copyright (C 2018 (SAGE Publications). DOI: 10.1177/0149206315602531

Intervening to Enhance Proactivity in Organizations: Improving the Present or

Changing the Future

Karoline Strauss

ESSEC Business School

Sharon K. Parker

UWA Business School, University of Western Australia

Corresponding author: Karoline Strauss, ESSEC Business School, Avenue Bernard Hirsch, 95021 Cergy-Pontoise Cedex, France

Email: strauss@essec.edu

In press at the Journal of Management 


\begin{abstract}
A growing body of evidence has linked proactivity at work to positive outcomes. Yet little research to date has investigated whether employees' proactive behavior in organizations can be facilitated through training and development. Nor has research considered which variables shape employees' responses to such interventions. We investigate the effects on proactivity of two theoretically distinct training and development interventions in a randomized field experiment with police officers and police support staff $(\mathrm{N}=112)$. We hypothesized that a problem-focused intervention, which made discrepancies between the status quo and the ideal present more salient, would lead to increases in individual task proactivity; whereas a visionfocused intervention, which made discrepancies between the status quo and an ideal future more salient, would increase organization member proactivity. Intervention effects were moderated by role overload and future orientation, respectively. Only individuals with high levels of role overload increased their individual task proactivity as a result of the problemfocused intervention, and only individuals high in future orientation increased their organization member proactivity as a result of the vision-focused intervention. Our study integrates different cybernetic perspectives on how proactivity is motivated, and provides novel insights into moderators of interventions designed to capture these different mechanisms. From a practical perspective, our study supports organizations seeking to implement training and development interventions, and helps them to determine who might benefit most from interventions.
\end{abstract}

Keywords: proactive behavior, training and development, field experiment, future work self, resources 


\section{INTERVENING TO ENHANCE PROACTIVITY IN ORGANIZATIONS: IMPROVING THE PRESENT OR CHANGING THE FUTURE}

Proactivity refers to individuals "taking initiative in improving current circumstances or creating new ones; it involves challenging the status quo rather than passively adapting to present conditions" (Crant, 2000). A proactive approach towards work has been linked to many positive outcomes (for meta-analyses see Fuller \& Marler, 2009; Thomas, Whitman \& Viswesvaran, 2010), including job performance (Thompson, 2005), and innovation (Kickul \& Gundy, 2002). Proactive behavior constitutes a critical aspect of work performance, particularly in unpredictable organizational contexts where it is not possible to anticipate and pre-specify ways in which individuals can contribute to organizational effectiveness, (Griffin, Neal \& Parker, 2007). Altogether, there is substantial evidence that 'proactivity matters'.

Many studies have investigated the antecedents of proactivity (see Bindl \& Parker, 2011; Parker, Bindl \& Strauss, 2010, for reviews). Previous research has identified that individual differences (e.g., proactive personality, Fuller \& Marler, 2009) and contextual factors (e.g., job autonomy, Parker, Williams \& Turner, 2006) can facilitate proactivity (Parker et al., 2010). However, although there are a few exceptions that we discuss shortly (Friedrich, Glaub, Gramberg \& Frese, 2006; Raabe, Frese \& Beehr, 2007; Searle, 2008), little research has investigated whether it is possible to train individuals to be more proactive.

Neglecting to evaluate the role of training and development interventions for enhancing proactivity is a significant omission. To date, for organizations wishing to increase the proactivity of their workforce, existing research suggests either a selection approach (i.e., hiring individuals with particular personalities and abilities) or changing the work context (e.g., enriching work). The former strategy depends on the opportunity for hiring, which often does not exist, and the latter can be challenging and even impossible in some contexts (e.g., Parker \& Wall, 1998). In contrast, training and development represents a pervasive strategy in organizations, suggesting it is considered a feasible approach for promoting change in work 
behaviors. In the US alone, organizations spent over $\$ 165$ billion on employee training and development in 2013 (Association for Talent Development, 2014). It is thus important to understand whether training can be used to enhance proactivity at work.

Previous intervention studies aimed at enhancing proactivity have mostly drawn on German action theory (Frese \& Zapf, 1994). This theory proposes that goal-directed behavior such as proactive behavior involves the action sequences of developing goals, collecting information, generating and executing plans, and processing feedback (Frese \& Zapf, 1994). Increasing the commitment to goals and improving the quality of knowledge and information and thus the quality of plans are expected to make it more likely for participants to become proactive (Raabe et al., 2007). Correspondingly, participants were trained to set goals, plan for obstacles, and monitor progress. Friedrich and colleagues (2006) found that South African entrepreneurs reported an increase in performance six months after the proactivity training, compared to a no-treatment control group. Glaub, Frese, Fischer, and Hoppe (2014) found an increase in Ugandan entrepreneurs' personal initiative, assessed in interviews, four to five months after the proactivity training, compared to a control group. In contrast, a study by Searle (2008) failed to find effects of a similar training intervention on self-reported personal initiative in college students. Finally, Raabe and colleagues (2007) conducted the only previous intervention study on proactivity in organizations, albeit focused only on careerrelated proactivity. In a sample of 205 white collar workers in Germany, these authors found significant gains in the quality of participants' career plans following the intervention, which was in turn related to proactive career behavior assessed after three months. However there was no control group in this study, which limits the causal interpretations that can be made.

Taken together these studies provide some initial support for the possibility that proactivity in organizations can be enhanced through training interventions, and highlighted the importance of an action sequence consisting of goal setting, planning, and reflecting (Frese \& Zapf, 1994). However, these studies have paid little attention to how goals are 
generated, have not considered effects on different types of proactive behavior, and they have not investigated whether the interventions are equally effective for all individuals.

Our paper addresses these gaps. We investigate the effects on proactivity of two distinct training and development interventions in comparison to a control group: a problemfocused intervention and a vision-focused intervention. Both interventions aim to enhance proactivity, but their designs reflect different cybernetic models of behavior that, in turn, imply different resource management strategies and hence prompt different types of proactive behavior. Cybernetic models propose that individuals compare their perception of their current situation to a reference value (Carver \& Scheier, 1982). From this perspective, proactive behavior is a way to reduce discrepancies between the current situation and a reference value. We integrate this perspective with conservation of resources (COR) theory (Hobfoll, 1989) to propose that interventions focusing on ideal present versus ideal future reference values invoke strategies aimed at protecting current resources versus accumulating future resources, respectively, which in turn prompts different types of proactivity.

Importantly, we do not expect all individuals to be equally responsive to the interventions. Thus we identify moderators of intervention effects. Although some studies have found that the impact of antecedents on proactivity is moderated by individual differences (e.g., Griffin, Parker \& Mason, 2010), we know almost nothing about individual differences that shape how people respond to proactivity-focused training interventions. Drawing on recent extensions of COR theory (Halbesleben \& Wheeler, in press), we expect distinct moderators for the two interventions, as we elaborate shortly.

Our study contributes to the literature in several ways. We seek to demonstrate not only that it is possible to promote proactivity via a training and development intervention, but that interventions designed with distinct reference values, from a cybernetic and a resource management perspective, promote different types of proactivity. We thus enhance our theoretical understanding of proactivity and how this type of behavior might be developed. 
Our research also investigates who responds best to these interventions, and in doing so, expands theory regarding boundary conditions of proactivity interventions. From a practical perspective, our study helps organizations seeking to implement training interventions to determine whom to target with which intervention.

\section{Proposed Theoretical Processes: Discrepancy Reduction and Resource Management}

Proactivity can be understood from a cybernetic control perspective. Control theory (Carver \& Scheier, 1982; 1998) proposes that "much of human behavior consists of attempts to create and maintain conformity to desired goal values", and that feedback loops form the basis of self-regulated behavior (Carver, Sutton \& Scheier, 2000). As a first step, individuals form a perception of the current situation. This perception is then compared against a reference value, such as one's idea of the ideal situation. When individuals detect a discrepancy between their perception of the current situation and the reference value, behavior to reduce the discrepancy is triggered (Carver \& Scheier, 1982; 1998). An example of the principles of control theory is a thermostat (Klein, 1989): a sensor monitors the temperature of the room (current situation), and this value is compared with the temperature at which the thermostat is set (reference value). When the current and desired temperatures differ, an air conditioner or heater is activated to reduce the discrepancy.

From this cybernetic perspective, proactivity can be considered as a way to reduce discrepancies between the current situation and a reference value. Although several authors refer to proactivity from this perspective, they differ with respect to the type of reference values that are thought to motivate proactive behavior. Some focus on reference values reflecting a desired present (Fay \& Sonnentag, 2002) whereas others focus on a desired future (Griffin et al., 2010; Strauss, Griffin \& Parker, 2012). We extend theory on proactivity by reconciling these different perspectives, and by integrating them with COR theory.

COR theory proposes that individuals are motivated to protect their current resources as well as to accumulate resources for the future (Hobfoll, 1989, 2001). Resources are broadly 
defined as "objects, personal characteristics, conditions, or energies that are valued by the individual" (Hobfoll, 1989). Proactivity can be a way to manage one's resources. Ng and Feldman (2012) argued that individuals might strategically use voice, a type of proactive behavior (Parker \& Collins, 2010), to protect or acquire resources. Parker and colleagues similarly argued that individuals engage in proactive behavior to "exert control over the environment so as to gain new resources that equip them for future challenges" (Parker, Johnson, Collins \& Hong, 2013). But although scholars have suggested that proactive behavior can be a resource management strategy, we know little about which proactive behaviors reflect resource protection or accumulation, or when individuals are likely to be proactive to protect their current resources versus building future resources.

We argue that different reference values have distinct implications for resource management, and hence prompt different types of proactive behavior. Following Boldero and Francis (2002), we distinguish between positive reference values reflecting desired states in the present and desired states in the future. Our focus is distinct from other conceptualizations of reference values in self-regulation, for example, reference values representing obligations versus aspirations (Higgins, 1998), or positive versus negative reference values (Carver \& Scheier, 1982; Elliot, Sheldon \& Church, 1997). We argue that reference values representing desired states in the present and in the future can both stimulate proactive behavior, albeit different forms, and that different boundary conditions will be at play.

First, reference values can be present-focused, concerned with what is acceptable or desired in the current situation (Boldero \& Francis, 2002). In this case, proactivity is focused on reducing the discrepancy between the current situation and an ideal present (Fay \& Sonnentag, 2002). We extend this argument and suggest that when discrepancies between the current situation and a desired present are salient, this is experienced as a negative psychological state (Boldero \& Francis, 2002), and is likely to motivate proactive behavior aimed at protecting current resources (Hobfoll, 1989). Specifically, we propose that when a 
discrepancy between the current situation and an ideal current work situation is salient, individuals will be motivated to engage in individual task proactivity, that is, proactive behavior aimed at optimizing the way they complete their individual tasks by modifying how they go about their work (Griffin et al., 2007). For example, if an individual's current work situation involves constantly reacting to demands, whereas their ideal present involves time for strategic planning, they might seek to reduce this discrepancy by proactively increasing the efficiency of their work methods to allow more time for planning. In this way, they protect their time 'resource'. The problem-focused intervention is consistent with this theoretical process as it encourages individuals to identify and remove undesirable aspects of their work. Second, reference values can be focused on the longer-term ideal future, rather than present ideals (Boldero \& Francis, 2002). We suggest that discrepancies between the current situation and an ideal future will stimulate proactive behavior aimed at building future resources, which is rather more risky than proactive behavior focused on protecting resources. Accumulation-oriented proactivity is risky because it is based on uncertain predictions about which resources will be of value in the future, whereas protecting resources against present losses deals with already-known threats. Importantly, we propose the focus on a longer-term ideal future means that individuals are likely to be more willing to engage in this more risky proactive behavior aimed at accumulating future resources. As argued by Strauss et al., (2012), a focus on the self in the longer-term future has a number of self-regulatory benefits. First, such "future work selves" are positive and linked into one's core values, which acts as a powerful motivational resource for engaging in activities that might otherwise be challenging. Second, the long-term focus facilitates the setting of more ambitious goals to get to the future self becaus temporal distance "affords individuals greater opportunity for taking risks" (Pennington \& Roese, 2003). Third, the focus on the future results in mental simulation as to how to get to the ideal self, which helps individuals to rehearse what resources they will need. 
Strauss et al.'s (2012) findings provide initial support for this idea that focusing on a long-term positive future stimulates proactivity aimed at accumulating future resources. Strauss et al. showed that individuals with a clear and accessible vision of their future work self were more likely to be engage in proactive skill development. Proactive skill development involves building career-relevant resources such as skills and experiences required in the future, rather than in one's current job (Claes \& Ruiz-Quintanilla, 1998). It thus reflects efforts to accumulate future resources.

A further proactive behavior likely to arise from discrepancies between the current situation and an ideal future is organization member proactivity, or proactivity intended to change the organization and/or the way the organization works (Griffin et al., 2007). Such behavior is broader in focus than individual task proactivity, and is also riskier, since it involves contributing at higher levels and therefore requires navigating system complexities. For example, when focusing on his or her long-term future work self, a nurse might be reminded of his or her values regarding high-quality patient care, which might stimulate the nurse to get engaged in hospital-wide improvement activities. Involving oneself in making the hospital a better place is likely to provide a range of avenues for resource accumulation. Individuals engaging in organization member proactivity may gain power and influence and "place themselves in positions that allow for [...] resource maximisation" (Hobfoll, 2001).

In sum, we propose that when individuals contrast the current situation with the ideal present (via a problem-focused intervention), this will stimulate individual task proactivity because individuals want to protect their current resources and optimize how they do their work. When individuals contrast the present with a vision of their ideal future in the long term (via a vision-focused intervention), this motivates them to think beyond their current job role, triggering an interest in changing the wider organization and in preparing for future challenges, thus stimulating proactive skill development and organization member proactivity. The hypotheses are: 
Hypothesis 1a: The problem-focused proactivity intervention will result in increased individual task proactivity.

Hypothesis 2a: The vision-focused proactivity intervention will result in increased proactive skill development.

Hypothesis 3a: The vision-focused proactivity intervention will result in increased organization member proactivity.

We further argue that these expected effects of the interventions will be moderated by individual and contextual factors, specifically, role overload and future orientation. Our hypotheses are summarized in Figure 1. We elaborate the moderation hypotheses next.

Insert Figure 1 about here

\section{Moderators of Intervention Effects: Role Overload and Future Orientation}

Because of the resource management processes underpinning the interventions that we discussed above, we expect some individuals be more strongly influenced by the interventions than others. Resource management behavior is shaped by two factors: individuals' perceptions of the availability of resources, and their beliefs about the instrumentality of investing in future resources (Halbesleben and Wheeler (in press). We focus on two moderators that capture these different factors, role overload and future orientation, respectively, and argue that these constitute boundary conditions that shape the effects of the interventions.

First, we propose that role overload determines whether individuals respond positively to the problem-focused intervention by engaging in proactive behavior aimed at protecting their resources. Role overload reflects a "lack of adequate resources required to comply with role expectations or demands" (Abdel-Halim, 1978, p. 565). For individuals with high role overload, discrepancies between the actual and the desired present are likely to be particularly 
salient. These individuals are likely to experience their available resources as limited and so will be motivated to protect and conserve their resources by optimizing their use (Hobfoll, 1998). Halbesleben and Bowler (2007) argued that individuals experiencing resource threat, such as high levels of role overload, seek to protect their resources by putting less effort into behaviors they are not required to perform. Based on this argument that resource protection is likely to trigger an increased focus on the core task, we suggest that individuals experiencing role overload will protect their current resources by focusing on the tasks they are required to perform, and finding more efficient ways of performing these tasks. On the other hand, individuals with low role overload are unlikely to experience significant discrepancies between the actual and ideal present. They are likely to perceive their available resources as sufficient and will be less motivated to proactively protect their current resources by optimizing the way they go about their job. In sum, we propose that role overload will moderate the effect of the problem-focused intervention on individual task proactivity:

Hypothesis 1b: The effect of the problem-focused proactivity intervention on individual task proactivity will be stronger for individuals with high role overload relative to those with low role overload.

Second, individuals make strategic judgments about the instrumentality of investing in future resources (Halbesleben \& Wheeler, in press), and these decisions are influenced by individual differences (Grawitch, Barber \& Justice, 2010). We propose that individuals' efforts to build future resources will be influenced by their future orientation, or their stable beliefs in the benefits of investing in future resources (Strathman et al., 1994). Highly futureoriented individuals will respond more positively to a vision-focused intervention that makes discrepancies between the current situation and the desired future salient. Future-oriented individuals are more aware of the consequences of their actions for future resources, and tend to value these consequences more (Joireman, Strathman \& Balliet, 2006b). Such individuals generally focus on working towards an ideal future (Joireman, Kamdar, Daniels \& Duell, 
2006a), and respond favorably to health messages emphasizing long-term positive effects on resources and short-term negative effects (Orbell \& Kyriakaki, 2008). Highly future-oriented individuals will also be more able to envision the future, and thereby more able to anticipate future resource requirements (Strauss et al., 2012). They are thus more likely to want to accumulate future resources in response to discrepancies between the status quo and an ideal future, and so will enhance their proactive skill development and organization member proactivity as a result of the vision-focused intervention.

On the other hand, for individuals low in future orientation the short-term costs of investing in future resources will outweigh the long-term benefits. They are less likely to be able, or motivated, to address future-focused discrepancies and to build resources for the future. For these individuals, investing effort into the development of skills that are not useful in their current job but in future positions will seem like a costly strategy that is unlikely to pay off. Similarly, they will pay more attention to the short-term risks of attempting to shape the future of the organization rather than to the potential long-term benefits.

In sum, we expect that individuals high in future orientation will be motivated to address discrepancies between their current situation and an ideal future by engaging in proactive behavior aimed at building future resources. Individuals low in future orientation are unlikely to be motivated to address these discrepancies. Our hypotheses are:

Hypothesis 2b: The effect of the vision-focused proactivity intervention on proactive skill development will be stronger for individuals with high future orientation than those with a low future orientation.

Hypothesis 3b: The effect of the vision-focused proactivity intervention on organization member proactivity will be stronger for individuals with high future orientation than those with a low future orientation.

\section{METHOD}


We compared the effects of the problem-focused intervention and the vision-focused intervention with a control group that received no intervention. Experimental designs involving control groups establish causality more strongly than other approaches (Cook \& Campbell, 1979). For example, with regards to proactivity, proactive individuals might be more likely to take part in, and respond positively to, training and development initiatives. Field experiments with participants randomly allocated to control/comparison conditions make it possible to rule out such selection effects (Cook \& Campbell, 1979).

\section{Sample and Procedure}

Participants were recruited from a territorial police force in England. Participation was voluntary. There was neither a sanction for not participating nor a reward for participation. One hundred twelve volunteers signed up to the study by contacting an internal project manager following an email inviting employees to participate in a training program which "has been developed to help people at work become happier and healthier, and aims to provide $[\ldots]$ an opportunity for personal growth”. Volunteer participants were randomly assigned to one of three conditions: The problem-focused intervention, the vision-focused intervention, and a no-treatment control group. Participants in the two intervention groups were given the same explanation regarding the focus and intended outcome of the training, i.e., "supporting you in becoming active in making changes so that you feel happier at work". Within each of the intervention groups, participants took part in a one-day workshop followed by a half-day workshop two months later, in cohorts of approximately 20 individuals. The longitudinal design of the study consisted of a pre-test just before the first workshop (T1; N = 111), and two post-tests. The first post-test $(\mathrm{T} 2 ; \mathrm{N}=87)$ took place just before the second workshop, two months after the first workshop; the second post-test (T3; $\mathrm{N}=76)$ took place three months after the second workshop. We expected that behavior change in response to different types of discrepancies would take some time to occur. Our design allowed us to assess how effects developed over the course of the program. 
At T1, 54.5\% of respondents were female. Respondents were between 21 and 58 years old, with an average age of $39.31(\mathrm{SD}=8.27)$. Average tenure in the organization was 10.66 years $(\mathrm{SD}=8.22)$. There were no significant differences in these demographics across the three groups ${ }^{1}$. To further check the internal validity of the design and the success of the random allocation, we compared the three groups on key study variables at T1. No significant differences were found between the groups at $\mathrm{T}^{2}$, suggesting that the random assignment had been successful in establishing initial equivalence between the three groups.

We conducted a chi-square test to detect whether participants in any particular group were more likely to be missing at $\mathrm{T} 2$ or $\mathrm{T} 3$. Neither missingness at $\mathrm{T} 2\left(\chi^{2}(2, \mathrm{~N}=111)=1.46\right.$, $p=.48)$ nor missingness at $\mathrm{T} 3\left(\chi^{2}(2, \mathrm{~N}=97)=0.90, p=.64\right)$ was significantly related to assigned membership in the three groups. Participants who were missing at T2 or at T3 did not significantly differ from respondents in the outcome variables at $\mathrm{T}^{3}$. Thus, attrition did not seem to be related to key study variables.

Over the course of the study, the job of one participant in the problem-focused intervention, three participants in the vision-focused intervention, and seven participants in the control group, changed ${ }^{4}$. Because these employees were likely to undergo a period of role ambiguity and adjustment (Saks, Uggerslev \& Fassina, 2007), which might cause changes in these employees' behavior (Jackson \& Schuler, 1985) that were unrelated to the interventions, we excluded these eleven participants from subsequent analyses.

Problem-focused intervention. The problem-focused intervention was designed to enable participants to actively reduce discrepancies between the current situation and the desired present by addressing current problems. Participants reflect on current aspects of their job that are not ideal, and set goals to proactively address these aspects. The intervention was based on established individual-focused interventions aimed at promoting an active approach to addressing job factors that drain individuals' resources (Bond \& Bunce, 2000; Bunce \& West, 1996). 
The intervention consisted of one full-day workshop followed by a half-day workshop two months later. The first workshop opened with an introduction about recognizing symptoms caused by problems at work. Participants were asked to reflect on factors in their job and work environment that were not ideal and thus posed threats to their resources. Similar to Bunce and West (1996), we then introduced "making changes at work" as a way to deal with these threats. Group discussions and brain storming exercises were aimed at generating possible ways of making changes. Participants then set themselves up to four goals aimed at protecting their resources by initiating change.

We incorporated goal setting into both interventions because it is widely recognized as facilitating training transfer (Taylor, Russ-Eft \& Chan, 2005) and as stimulating behavior change (Wexley \& Baldwin, 1986). In accordance with goal setting research (Bandura, 1977; Locke \& Latham, 1990, 2002), participants were asked to set goals that were specific and achievable. Based on research on approach- and avoidance motivation, positive goals have a greater motivational effect (Elliot, 1999), so participants were also advised to set positive goals. Similar to the procedure outlined by Morisano and colleagues (2010), participants ranked their goals in terms of their importance. The goal identified as most important was broken down into sub-goals, as recommended by Stock and Cervone (1990). Participants were encouraged to do the same for their remaining goals in their own time. Goal progress was further supported by implementation plans. That is, participants specified how and when they would pursue a sub-goal (Gollwitzer, 1999). Finally, to enhance goal striving participants were asked to share their most important goal with the group and express their level of commitment. To help participants to address some of the most common threats to their resources such as high demands (Michie \& Williams, 2003), the first workshop included time management training, as well as assertiveness training aimed at encouraging individuals to "say no" in order to protect their resources. 
In the second workshop participants first shared any progress towards their goals with the group. This was intended to encourage individuals to sustain their efforts towards bringing about their ideal present. Persistence was also expected to be enhanced through positive feedback from the group and social persuasion about the likelihood of future success (Bandura, 1982). Participants reflected on obstacles they encountered in protecting their resources, and identified possible ways of overcoming them. Because workplace relationships play a critical role for individuals' resources (Halbesleben \& Wheeler, in press) the second workshop also contained training on effectively handling interpersonal conflict at work.

Vision-focused intervention. The vision-focused intervention was designed to encourage individuals to address discrepancies between the current situation and their envisioned future. We drew specifically on prior evidence that a salient 'future work self' can stimulate proactivity (Strauss et al., 2012). Future work selves are "representations of the self in the future that encapsulate individually significant hopes and aspirations in relation to work" (Strauss et al., 2012, p. 581). Our intervention encouraged individuals to visualize their future work self and set goals to move towards the future they envision.

Like the problem-focused intervention, this intervention consisted of one full day workshop followed by a half day workshop two months later. In the first workshop, participants were expected to envision their future work self. They were first asked to reflect on positive experiences they have had at work. This was intended to focus participants' attention on their preferences and values in relation to work and thus to facilitate the envisioning of their desired future working life. Participants then drew a picture of their future work self to enable them to engage with their aspirations for the future in a languageindependent way (Schyns, Tymon, Kiefer \& Kerschreiter, 2013). This activity was also intended to broaden individuals' thinking about future possibilities and to encourage a playful approach to their future self (Strauss et al., 2012). Future work selves were contrasted with drawings of participants' current self. This enabled participants to identify discrepancies 
between their current resources and future resource requirements and lay the basis for the generation of goals aimed at addressing these discrepancies. Participants then described a day in the life of their future work self which they shared with other group members. Describing a day in the life of their future work self was intended to enable participants to mentally simulate and "pre-experience" their desired future (Atance \& O'Neill, 2001), which is expected to further enhance the quality of their plans to work towards this future (Strauss et al., 2012). Finally, participants wrote down a summary of the future they envisioned.

Corresponding to the problem-focused intervention, participants were then instructed to set themselves up to four goals aimed at moving them towards their future work self. As in the problem-focused intervention, participants set specific, positive and attainable goals; identified sub-goals; developed implementation plans; and shared their goals with others. Having generated their goals, participants then underwent a pathways exercise in relation to the goal they had selected as most important. In parallel to the brainstorming exercise in the problem-focused intervention, they were then asked to generate as many obstacles as possible in relation to their goals and, with the help of other workshop participants, to find ways around each obstacle. Contrasting fantasies about a desired future with reflections on constraints that impede its realization is critical for individuals' self-regulation (Oettingen, Pak \& Schnetter, 2001). Research on fantasy realization theory (Oettingen, 1999, 2000) shows that positive fantasies about the future need to be contrasted with negative reflections on reality impeding this future. Individuals then decide "whether the desired future can be realized by overcoming the present obstacles" (Oettingen, Mayer, Thorpe, Janetzke \& Lorenz, 2005), and goal-directed energy is mobilized (Oettingen, Mayer, Timur Sevincer, Stephens, Pak \& Hagenah, 2009). In contrast, indulging in positive fantasies alone does not create a necessity to act (Oettingen et al., 2001). Based on these considerations, we encouraged participants to reflect on obstacles that could prevent their desired future from becoming reality, and then to actively plan how to address these obstacles. 
A further exercise to encourage participants to persist in the face of obstacles was based on a cognitive-behavioral intervention developed by Seligman (Reivich, Seligman \& McBride, 2011; Seligman, 2006). Participants identified their explanatory beliefs in relation to negative events (Weiner, 1985), and were encouraged to question beliefs that the causes of negative events are internal, universal, and permanent (Seligman, 2006). Explanatory beliefs that are optimistic rather than pessimistic are associated with greater persistence in the face of obstacles (Seligman \& Schulman, 1986). A similar approach was used in Friedrich and colleagues' (2006) intervention intended to enhance proactivity in entrepreneurs. Drawing on Ellis (1965), participants in Friedrich et al.'s intervention learned to question their beliefs and interpretations of a situation which would prevent them from attaining their goals.

As in the problem-focused workshop, in the second workshop participants reviewed their goal progress to date. Further pathways exercises in relation to goals were intended to sustain continued striving towards the future work self. As in the first workshop, contrasting visions of the desired future with obstacles was expected to mobilize goal-directed energy (Oettingen et al., 2009). In order to motivate efforts to deal with setbacks, participants then reflected on past experiences of successfully recovering from setbacks and identified successful strategies to deal with adverse events (c.f. Latack, 1986).

Equivalence of the interventions. Since both interventions involved goal setting as a mechanism to facilitate change, it was important to establish that goal-directed effort and goal progress were equivalent between the two interventions. At T3, participants were presented with the goals they had set in the first workshop and rated the amount of effort they had put into striving for these goals, and the amount of progress they had made towards them. Goaldirected effort ( $\alpha=.91)$ was assessed using two items adapted from Sheldon and Elliot (1999). The items were: "How hard have you been trying to achieve this goal?" (rated on a scale ranging from 1 "not at all hard" to 7 "very hard"), and "To what extent have you persisted to achieve this goal? " (rated on a scale ranging from 1 "not at all" to 7 "a very large 
extent"). These items were averaged over the four goals. Goal progress $(\alpha=.90)$ was measured with two items by Sheldon and Elliot (1999), rated on a 5-point scale ranging from 1 "strongly disagree" to 5 "strongly agree". The items were: "I have made considerable progress toward attaining this goal" and "I accomplished what I set out to do with this goal".

There were no significant differences in these goal variables between the problemfocused intervention and the vision-focused intervention (goal-directed effort: $t(39)=0.38, p$ $=.71$; goal progress: $t(38)=0.11, p=.91)$. Goal effort and goal progress were thus unlikely to account for any differences between the two intervention groups.

An overview of the elements of both interventions is shown in Table 1.

Insert Table 1 about here

To minimize differences in delivery, the format, venues, and timings of the cohorts within the two intervention groups were kept parallel; training programs involved the same amount of time ${ }^{5}$; and all workshops were delivered by the same two facilitators. Facilitators were aware that both interventions were intended to result in behavior aimed at initiating change but were blind to the specific hypotheses. To exclude the possibility of systematic differences in the quality of the programs, we assessed participants' reactions to the workshops. After each workshop, participants responded to nine items by Warr et al. (1999), assessing training reactions. Responses were rated on a 5-point scale ranging from "strongly disagree" (1) to "strongly agree" (5). There were no differences between the intervention groups in enjoyment $(t(50)=-1.28, p=.21)$, perceived usefulness $(t(50)=0.08, p=.94)$, and perceived difficulty $(t(50)=0.80, p=.43)$ of the programs. Means scores suggested that participants across the two groups found the training enjoyable $(M=3.71, S D=0.66)$, useful $(M=3.57, S D=0.60)$, and moderately challenging $(M=1.72, S D=0.57)$.

No-treatment control group. At the time of the study, the organization underwent unprecedented change following the announcement of budget cuts in the public sector. For 
example, promotion boards were cancelled and teams were restructured. It was thus critical to establish that any change in our outcome variables was due to the interventions rather than other changes. A no-treatment control group allowed us to control for the effect of any cooccurring changes and to isolate intervention effects. In our analyses we used this notreatment control group as the reference category.

\section{Measures}

Unless otherwise stated, respondents rated items on a 5-point scale ranging from "Not at all" (1) to "A great deal" (5).

Role overload ( $\alpha=.86)$ was assessed at T1 with five items by Caplan and colleagues (Caplan, Cobb, French, Harrison \& Pinneau, 1975). A sample item is “To what extent do you find work piles up faster than you can complete it?"

Future orientation $(\alpha=.68)$ was measured at T1 with three items used to assess this concept by Strauss et al. (2012). A sample item is "I consider how things might be in the future, and try to influence those things with my day to day behavior." Items were rated on a 5-point scale ranging from "strongly disagree" (1) to "strongly agree" (5).

Individual task proactivity (T1: $\alpha=.91 ; \mathrm{T} 2: \alpha=.93 ; \mathrm{T} 3: \alpha=.93)$ was assessed with the three-item scale by Griffin et al. (2007) which captures the extent to which individuals initiate change in order to improve the way in which their core tasks are performed. The items are "(Over the past few weeks, to what extent have you): Come up with ideas to improve the way in which your core tasks are done?", "Made changes to the way your core tasks are done?", and "Initiated better ways of doing your core tasks?"

Proactive skill development (T1: $\alpha=.91 ; \mathrm{T} 2: \alpha=.94 ; \mathrm{T} 3: \alpha=.94)$ was measured with three items by Claes and Ruiz-Quintanilla (1998). The items are "(Over the past few weeks, to what extent have you) Developed skills which may be need in the future?", “Gained experience in a variety of tasks to increase your knowledge and skills?", and "Developed knowledge and skill in tasks critical to your future work life?" 
Organization member proactivity (T1: $\alpha=.87 ; \mathrm{T} 2: \alpha=.93 ; \mathrm{T} 3: \alpha=.93)$ was measured with three items by Griffin et al. (2007) which assess individuals' efforts to initiate changes in the way their organization operates. This measure reflects efforts to shape the future of one's organization in a positive way. The items are "(Over the past few weeks, to what extent have you) Come up with ways of increasing efficiency within the organization?", "Made suggestions to improve the overall effectiveness of the organization (e.g., by suggesting changes to administrative procedures)?", and "Involved yourself in changes that are helping to improve the overall effectiveness of the organization?"

Demographics. Demographic variables collected included participants' age, gender, and tenure in the organization.

\section{Analysis}

To establish the discriminant validity of the study constructs we conducted a series of confirmatory factor analyses in MPlus7 (Muthén \& Muthén, 2012), using maximum likelihood estimation. A five-factor model distinguishing between role overload, future orientation, and the three behavioral outcomes at $\mathrm{T} 1$ showed an excellent fit $\left(\chi^{2}=135.46, d f=\right.$ $109, p<.05 ; \mathrm{CFI}=.97 ; \mathrm{RMSEA}=.05 ; \mathrm{SRMR}=.06)$. This model fit the data significantly better than competing models, including a one-factor model $\left(\chi^{2}=747.16, d f=119, p<.001\right.$; $\left.\mathrm{CFI}=.38 ; \mathrm{RMSEA}=.22 ; \mathrm{SRMR}=.19 ; \Delta \chi^{2}(10)=611.70, p<.001\right)$, and a three-factor model in which all items assessing behavioral outcomes were specified to load onto one factor $\left(\chi^{2}=451.87, d f=116, p<.001 ; \mathrm{CFI}=.67 ; \mathrm{RMSEA}=.16 ; \mathrm{SRMR}=.12 ; \Delta \chi^{2}(7)=316.41, p\right.$ $<.001)$. We concluded that the five study constructs are distinct factors.

Multilevel regression analyses in SPSS18 were employed to test the effects of the intervention programs. In multilevel analyses of longitudinal data, measurement occasions are nested within the individual (Raudenbush, 1989; Snijders, 1996). Following the procedure adopted by Le Blanc et al. (2007; see also Holman, Axtell, Sprigg, Totterdell \& Wall, 2010), we coded the three measurement occasions with two dummy variables, using the second 
measurement occasion as the reference category. This allowed us to compare the first and second measurement occasion, and the second and third measurement occasion, respectively, and thus to explore whether any changes between $\mathrm{T} 1$ and $\mathrm{T} 2$ were sustained between $\mathrm{T} 2$ and T3. Membership in the three experimental groups was coded with two dummy variables, using the control group as the reference category. The first dummy variable thus allowed us to compare the problem-focused intervention with the no-treatment control group; the second dummy variable compared the vision-focused intervention to the no-treatment control group. Accordingly, interactions between the dummy variables representing measurement occasions and the dummy variables representing group membership show differences between the trajectories of outcome variables between $\mathrm{T} 1$ and $\mathrm{T} 2$, and $\mathrm{T} 2$ and $\mathrm{T} 3$, respectively, across the different experimental groups.

This analysis approach is recommended for field experiments (Shadish, 2002). It is superior to repeated measures ANOVA because it does not require listwise deletion of data and makes weaker assumptions about the dropout process (Hox, 2002). It thus enabled us to include as many data points as possible by dealing effectively with missing data. This approach also allowed us to compare both intervention groups to the no-treatment control group within the same model. Comparison to the control group is a key advantage of field experiments. In field experiments, intervention groups (in which change is expected) are compared to a no-treatment control group (in which no change is expected). If change in the dependent variable occurs in the intervention group, but not in the control group, this change can be attributed to the experimental intervention (Shadish, Cook \& Campbell, 2002).

Age, gender, and organizational tenure were included as control variables in all analyses. These level-1 control variables were grand mean centered before being entered into the regression equation (Hofmann \& Gavin, 1998). We controlled for age because prior research has shown that age affects individuals' future orientation in relation to their goals (Nurmi, 1992). Although findings regarding the relationship between proactive behavior and 
age are inconsistent (Bindl \& Parker, 2011), several studies found lower levels of proactive behavior in older employees (e.g., Axtell, Holman, Unsworth, Wall \& Waterson, 2000). Tenure in the organization also constitutes a potential confound; as tenure increases, individuals are less likely to initiate new approaches to work (Gilson \& Shalley, 2004). Finally, we controlled for gender because prior research has shown gender differences in future orientation (Petrocelli, 2003). Previous research also reports inconsistent findings regarding the relationship between gender and proactive behavior (Bindl \& Parker, 2011), with some studies reporting significant effects (Griffin et al., 2007).

\section{RESULTS}

Means and standard deviations of all variables are shown in Table 2. Table 3 shows their intercorrelations.

Insert Tables 2 and 3 about here

To investigate the main effect of the problem-focused intervention on individual task proactivity (Hypothesis 1a), we tested two-way interactions of the intervention (the dummy variable contrasting the problem-focused intervention and the control group) and time (the dummy variable contrasting T1 and T2, and the dummy variable contrasting T2 and T3, respectively). There were no significant time by intervention effects ( $\mathrm{T} 1 \mathrm{vs.} \mathrm{T} 2 \mathrm{~B}=-0.05, \mathrm{SE}$ $=0.29, t=-0.18, p=.86 ; \mathrm{T} 2$ vs. T3: $\mathrm{B}=0.32, \mathrm{SE}=0.31, t=1.03, p=.31)$. Hypothesis $1 \mathrm{a}$ was not supported. The vision-focused intervention also did not cause changes in individual task proactivity $(\mathrm{T} 1$ vs. $\mathrm{T} 2: \mathrm{B}=0.00, \mathrm{SE}=0.29, t=0.31, p=.76 ; \mathrm{T} 2$ vs. $\mathrm{T} 3: \mathrm{B}=0.05, \mathrm{SE}=$ $0.31, t=0.18, p=.86)$.

To test the moderating effect of role overload on the effects of the problem-focused intervention (Hypothesis 1b) we tested three-way interactions of the problem-focused intervention, time, and role overload. Role overload was grand mean centered (Hofmann \& Gavin, 1998). Results are shown in Table 4.The three-way interaction between the problem- 
focused intervention, time, and role overload in predicting individual task proactivity was significant $(\mathrm{B}=0.87, \mathrm{SE}=0.40, t=2.20, p<.05)$, indicating that between $\mathrm{T} 2$ and $\mathrm{T} 3$, participants in the problem-focused intervention and in the no-treatment control group showed different change trajectories in individual task proactivity, depending on their initial experience of role overload. There was no evidence of change from T1 to T2, suggesting that gains were observed over longer periods of time. The modeled change trajectories are shown in Figures 2 and 3. To facilitate interpretation only significant effects are displayed.

Insert Table 4 and Figures 2 and 3 about here

We tested the significance of the change between T2 and T3 for individuals high and low in role overload. We used the conventional values of one standard deviation above and below the mean of role overload. The slope for the high role overload group was positive and significant $(t=2.26, p<.05)$, indicating that individual task proactivity increased significantly between $\mathrm{T} 2$ and $\mathrm{T} 3$ for participants in the problem-focused intervention who initially experienced high role overload. For participants low in role overload, levels of individual task proactivity did not significantly increase $(t=0.49, p=.49)$. In the control group there was no change for either high or low role overload individuals in individual task proactivity $(t=-$ $0.84, p=.41$; and $t=0.28, p=.60$, respectively). Hypothesis $1 \mathrm{~b}$, that the problem-focused intervention would have stronger effects on individual task proactivity for individuals with high role overload relative to those with low overload, was thus supported. These effects were unique to the problem-focused intervention. In addition to there being no main effects, role overload did not moderate the effects of the vision-focused intervention on task proactivity.

Hypothesis 2a predicted that the vision-focused intervention would enhance proactive skill development. A main effect of the intervention would be reflected in significant time by intervention interactions. However, these were not significant (T1 vs. T2: $\mathrm{B}=0.08, \mathrm{SE}=.29$, 
$t=0.26, p=.70 ; \mathrm{T} 2$ vs. T3: $\mathrm{B}=0.18, \mathrm{SE}=.35, t=0.51, p=.61)$. The problem-focused intervention also did not lead to changes in proactive skill development ( $\mathrm{T} 1 \mathrm{vs}$. $\mathrm{T} 2 \mathrm{:} \mathrm{B}=-0.06$, $\mathrm{SE}=.30, t=-0.19, p=.85 ; \mathrm{T} 2$ vs. T3: $\mathrm{B}=0.37, \mathrm{SE}=.35, t=1.08, p=.28)$.

The three-way interactions between the vision-focused intervention, time, and future orientation in predicting proactive skill development were also not significant $(\mathrm{T} 1 \mathrm{vs}$. $\mathrm{T} 2$ : $\mathrm{B}=$ $0.23, t=0.48, p=.64$; T2 vs. T3: $\mathrm{B}=.42, t=0.72, p=.47)$. Hypothesis $2 \mathrm{~b}$, predicting a stronger effect of the vision-focused intervention on proactive skill development for individuals high in future orientation, was thus not supported.

Hypothesis 3a proposed that the vision-focused intervention would enhance organization member proactivity. Time by intervention interactions were not significant (T1 vs. $\mathrm{T} 2: \mathrm{B}=-0.11, \mathrm{SE}=.28, t=-0.40, p=.69 ; \mathrm{T} 2$ vs. $\mathrm{T} 3: \mathrm{B}=-0.20, \mathrm{SE}=.31, t=-0.66, p=$ $.51)$, failing to support the hypothesis. The problem-focused intervention also did not result in changes in proactive skill development (T1 vs. T2: $\mathrm{B}=-0.07, \mathrm{SE}=.29, t=-0.24, p=.81 ; \mathrm{T} 2$ vs. $\mathrm{T} 3: \mathrm{B}=-0.13, \mathrm{SE}=.31, t=-0.41, p=.68)$.

However, there was a significant three-way interaction in predicting organization member proactivity $(\mathrm{B}=-1.24, \mathrm{SE}=.45, t=-2.78, p<.01$; see Table 5), indicating different change trajectories in organization member proactivity between $\mathrm{T} 1$ and $\mathrm{T} 2$ for participants in the vision-focused intervention and in the no-treatment control group, depending on their future orientation. There was no evidence of further change from T2 to T3, suggesting that the initial gains in organization member proactivity were sustained, but not enhanced, over time. Figure 3 displays the change trajectories. Interaction effects involving the problem-focused intervention were not significant.

Insert Table 5 and Figure 3 about here

We next tested the significance of the change in organization member proactivity between $\mathrm{T} 1$ and $\mathrm{T} 2$ for individuals high and low in future orientation, using the conventional 
values of one standard deviation above and below the mean. The slope for the high future orientation group was positive and significant $(t=2.17, p<.05)$, indicating that organization member proactivity increased significantly between $\mathrm{T} 1$ and $\mathrm{T} 2$ for participants in the visionfocused intervention with a strong future orientation, supporting Hypothesis $3 \mathrm{~b}$. The slope for low future orientation was also significant but negative $(t=-2.62, p<.05)$, indicating a decrease in organization member proactivity for participants in the vision-focused intervention who were low in future orientation. As expected, there was no change in organization member proactivity for the control group for either high or low future orientation individuals $(t=-.96, p=.34$; and $t=-.17, p=.87$, respectively).

\section{DISCUSSION}

In this paper we investigated whether and for whom training and development can enhance different types of proactivity at work. Based on an integration of COR theory with cybernetic models of self-regulation, we developed two theoretically distinct interventions that we expected to motivate different proactive behaviors. We found that a problem-focused intervention that focused on discrepancies between the current situation and the ideal present led to increased individual task proactivity for some; while a vision-focused intervention which made discrepancies between the current situation and an ideal future salient increased organization member proactivity for some.

Exactly who responded positively via enhanced proactivity varied according to the focus of the intervention. As we expected, individuals experiencing high levels of role overload increased their individual task proactivity when participating in the problem-focused intervention. Individuals facing role overload likely experienced a discrepancy between the current situation and an ideal present which they were motivated to reduce. Those who did not experience role overload did not modify their proactive behavior in response to the intervention, which we suggest reflects these individuals' lower discrepancy between their 
current and ideal present, thereby reducing their motivation for engaging in proactive behavior aimed at protecting their current resources.

In addition, we found that individual differences in future-orientation moderated individuals' responses to the vision-focused intervention. Individuals high in future orientation who habitually prefer to invest in future rather than in current resources responded positively to the vision-focused intervention, increasing their levels of organization member proactivity and thereby involving themselves in shaping the future of the organization.

Our study contributes to research on proactive behavior in several ways. First, using a rigorous field experimental design, we have shown that it is possible to enhance different proactive behaviors through training and development. A small handful of studies to date have investigated whether it is possible to enhance proactive behavior through training and development (Friedrich et al., 2006; Raabe et al., 2007; Searle, 2008), but these studies have not considered individual differences or situational factors that determine the effectiveness of different intervention strategies. The main effects of our interventions were not significant, highlighting the importance of considering potential moderators. The effects of the proactivity interventions might not be universal, but contingent on individual and situational factors. This might explain findings by Searle (2008) whose intervention failed to impact proactivity.

Previous intervention studies also have not distinguished between different forms of proactive behavior. In contrast, we showed that two distinct theoretically-derived training interventions had unique effects on different proactive behaviors. As such, our study extends cybernetic perspectives on how proactivity is motivated. Some scholars have argued that proactivity is aimed at addressing current unsatisfactory situations (Fay \& Sonnentag, 2002), and studies have shown a positive relationship between stressors and proactive efforts to improve work methods (Fritz \& Sonnentag, 2009). Others have emphasized the importance of visions of the future for proactive behavior (Griffin et al., 2010; Strauss et al., 2012). However, research to date has not clearly distinguished between proactive behavior aimed at 
changing an unsatisfactory present, and proactive behavior aimed at bringing about an ideal future. We demonstrated that different proactive behaviors likely correspond with these different mechanisms. An intervention focused on reducing discrepancies between the status quo and an ideal present led to increased efforts to preserve resources and find more efficient ways to complete one's tasks, but did not affect proactive behavior aimed at accumulating future resources. An intervention based on discrepancies between the status quo and an ideal future led to a focus on bringing about positive change in the organization as a way to accumulate future resources. However, it did not lead to increases in proactive behavior aimed at protecting current resources. Neither intervention affected proactive skill development.

Our study also has implications for understanding goal processes. Goal setting and associated self-regulatory processes are central to proactivity (Crossley, Cooper \& Wernsing, 2013; Frese \& Fay, 2001; Parker et al., 2010), but researchers have paid little attention to how different types of goals can stimulate proactive behavior. Our results suggest that different reference values underlie different forms of proactive behavior. Our findings thus also have a potential application in broader goal setting research by highlighting the value of distinguishing between present and future ideal states as reference values. Whilst researchers have recognized that self-regulation is differentially affected by positive and negative reference values (Carver \& Scheier, 1982; Elliot et al., 1997), or obligations versus aspirations (Higgins, 1998), much less attention has been given to reference values reflecting an ideal present versus as ideal future (Boldero \& Francis, 2002).

Our findings also show that individual differences shape these theorized mechanisms underlying individuals' proactivity. Specifically, our study highlights the importance of future orientation, an individual difference that has received limited attention in the literature on proactive behavior to date. Previous research has shown that individuals high in future orientation are generally more likely to engage in proactive behavior (Parker \& Collins, 2010). We show that future orientation determines whether encouraging individuals to 
envision their future work self results in higher levels of organization member proactivity. This suggests that future orientation does not only stimulate proactive behavior but could possibly also act as a moderator between envisioning the future, and later stages of the proactive goal regulation process (Bindl, Parker, Totterdell \& Hagger-Johnson, 2012). Future research is needed to explore this possibility in more detail.

We also contribute to research on the relationship between future work selves and proactive behavior. Our findings help to establish a causal link between envisioning future work selves and engaging in proactive behavior, specifically, organization member proactivity. Establishing a link between future work selves and organization member proactivity is important because proactive behavior aimed at bringing about change in the organization can contribute to organizational effectiveness, particularly in unpredictable organizational environments (Griffin et al., 2007). Interestingly the vision-focused intervention did not enhance proactive skill development, even though previous research has found a link between future work selves and proactive career behavior (Strauss et al., 2012). In the present study, it is possible that the budget cuts implemented in the organization at the time of the study limited individuals' ability to increase their career-relevant knowledge, skills, and abilities. For example, training activities were put on hold. Organization member proactivity might have provided a better approach than skill development for reducing the discrepancy between the status quo and an ideal future as this type of proactivity captures efforts to influence the future of the organization, potentially shaping individuals' future work environments. Put another way, the vision-focused intervention might have activated individuals' desire to support their organization at an exceptionally tough time in its history, with the organization undergoing unprecedented levels of change, rather than activating their desire for proactive personal development.

For those low in future orientation, on the other hand, organization member proactivity declined over the course of the study. This might be because these individuals do 
not see investing in their future as instrumental or meaningful. As the vision-focused intervention made future-oriented behaviors more salient, these individuals may have decided to reduce, rather than increase, their investment in these behaviors. The lack of immediate rewards to be reaped from organization member proactivity may have resulted in these individuals scaling back on behaviors that seem ineffective because they do not see a payoff in the short term. This is in line with findings by Orbell, Perugini, and Rakow (2004) who showed that individuals low in future orientation responded less favorably to messages that emphasize long-term benefits and short-term costs. When confronted with information concerning the long-term positive consequences about a preventative health measure, participants low in future orientation seemed unable to avoid paying attention to its short-term negative consequence and generated negative thoughts about the health measure. Similarly, the vision-focused intervention is likely to have made the long-term benefits of proactive behavior more salient, but by encouraging participants to reflect on immediate obstacles the intervention will also have increased the salience of the short-term costs of proactivity. For individuals low in future orientation, this might have stimulated negative thoughts about proactive behavior, and thus led to a decrease in proactivity. Further research is needed to investigate this possible unintended consequence of the intervention.

\section{Limitations and Directions for Future Research}

The strengths of our study include its experimental design which rules out alternative explanations for differences between the three groups, and its organizational setting which strengthens the external validity of our findings. The distinct effects of the two resource-based interventions suggest that that our findings are unlikely to be accounted for by researcher demand effects, selection effects, or Hawthorne effects.

Our study has some limitations. First, we only explored relatively short-term intervention effects. The first follow-up took place three months after the first survey, and the second follow-up was conducted after a further three months. Previous intervention studies on 
proactivity use similar time frames. Raabe et al. (2007) assessed changes in behavior after three months. In Friedrich et al.'s (2006) study, effects on performance were assessed after six months. Our design is thus in line with previous research. However, longer-term effects of the interventions should be explored. Second, we found that significant changes in organization member proactivity occurred between $\mathrm{T} 1$ and $\mathrm{T} 2$, with no decline or further increase between T2 and T3, suggesting that early initial gains were sustained over time but not enhanced with further training and/or time. In contrast, individual task proactivity changed between $\mathrm{T} 2$ and T3, indicating that individuals either took longer to make changes in their core job and/or required additional training. Thus our findings showed that changes in different proactive behaviors unfolded differently. Further research is needed to tease out whether, for individual task proactivity, it was the follow-up workshop that mattered, or merely the passing of time. One possible explanation is that there were greater external obstacles to individual task proactivity than to organization member proactivity. When individuals change the way they perform their core tasks, this might be met by resistance (Wrzesniewski \& Dutton, 2001). It might have taken individuals longer to increase their levels of individual task proactivity. In contrast, in involving themselves in changes in the organization, making suggestions, and contributing to change initiatives, individuals may have been less dependent on others, and less likely to meet resistance. Further research is needed to explore this possibility, and other explanations for differences in changes of proactive behaviors over time.

Our study also focused exclusively on the effects of the interventions on proactivity. It is possible there were other positive effects. As previously discussed, individuals felt the interventions were useful, suggesting that they may have benefitted in some way that we did not capture here. Future research should explore effects beyond the outcomes considered here. Another direction for future research is to directly assess the cybernetic processes and resource management strategies that we designed the interventions to capture.

Our study participants did not differ from the overall organization in key demographics. 
However, we relied on volunteers, and it is possible that the resulting sample might not have been representative for the overall population in terms of, for example, their proactivity. The random allocation to conditions addresses concerns about intervention effects being due to the characteristics of study volunteers, but it is possible that participants responded differently to the interventions than non-volunteers would have. For example, individuals who volunteered to be in the study might have been more proactive and future focused than non-volunteers, making them more responsive to the intervention. Further research is needed to explore the generalizability of findings and investigate the effects of moderators we did not capture here.

Future research also should explore the generalizability of our findings to other settings. While future orientation is stable over the course of a year (Toepoel, 2010), individuals may experience events which influence the extent to which they consider the future consequences of their behavior (Strathman et al., 1994). If individuals repeatedly experience that their efforts to build future resources are fruitless, they might pay less attention to the future consequences of their behavior. Organizations vary in the extent to which they emphasize planning for the future (Schriber \& Gutek, 1987). Employees in highly future-oriented organizations may be more likely to consider the future consequences of their behavior (Fried \& Slowik, 2004). Future research might assess whether vision-focused proactivity training is more likely to have positive outcomes in such organizations.

We proposed that those high in future orientation would be more likely to believe in the value of investing in their future resources, resulting in greater gains in organization member proactivity. However, it could also be that future-oriented individuals found it easier to envision their future work self. Post-hoc analyses of reactions to the future work self intervention revealed however no differences in enjoyment $(t(24)=0.39, p=.70)$, perceived usefulness $(t(24)=-0.87, p=.39)$, and perceived difficulty $(t(24)=0.78, p=.44)$ between the high and low future orientation groups, created using a median split. However, we cannot rule out such explanations as to why future-oriented individuals benefited from the vision- 
focused intervention. We also do not know whether individuals actually progressed towards their future work selves, which is a further question for future research. Similarly, individuals high in role overload may have found an intervention aimed at protecting their current resources more useful. However, high and low role overload groups did not differ in their perceptions of the problem-focused intervention (enjoyment: $(t(24)=0.29, p=.77$; perceived usefulness $(t(24)=-0.44, p=.67)$, and perceived difficulty $(t(24)=0.68, p=.50)$, suggesting that training reactions are unlikely to account for our findings.

Further, drawing on recent research on COR theory (Halbesleben \& Wheeler, in press) we proposed distinct moderators for the two interventions. We argued that individuals who were currently experiencing resource threat, indicated by role overload, would respond to the problem-focused intervention by protecting their resources through task proactivity. In contrast, we expected participants in the vision-focused intervention who were high in future orientation to seek to enhance their future resources via organization member proactivity and proactive skill development. However, it is also plausible that individuals experiencing resource threat would respond less positively to a vision-focused intervention, or that those high in future orientation will be less motivated to protect their current resources. We did not find support for these alternative moderation effects. Future orientation did not moderate the effects of the problem-focused intervention on task proactivity ( $\mathrm{T} 1 \mathrm{vs} . \mathrm{T} 2 \mathrm{~B}=0.81, \mathrm{SE}=$ $0.49, \mathrm{t}=1.66, \mathrm{p}=.10 ; \mathrm{T} 2$ vs. $\mathrm{T} 3: \mathrm{B}=0.16, \mathrm{SE}=0.54, \mathrm{t}=0.29, \mathrm{p}=.78 ;$ full tables are available from the authors), and role overload did not influence the effects of the visionfocused intervention (proactive skill development: $\mathrm{T} 1$ vs. $\mathrm{T} 2 \mathrm{:} \mathrm{B}=-0.11, \mathrm{SE}=.28, \mathrm{t}=-0.39, \mathrm{p}$ $=.70 ; \mathrm{T} 2$ vs. $\mathrm{T} 3: \mathrm{B}=0.20, \mathrm{SE}=.36, \mathrm{t}=0.59, \mathrm{p}=.55 ;$ organization member proactivity: $\mathrm{T} 1$ vs. $\mathrm{T} 2: \mathrm{B}=0.03, \mathrm{SE}=.27, \mathrm{t}=0.10, \mathrm{p}=.92 ; \mathrm{T} 2$ vs. $\mathrm{T} 3: \mathrm{B}=0.34, \mathrm{SE}=.29, \mathrm{t}=1.17, \mathrm{p}=.25)$. This further supports the distinct effects of the two moderators on the interventions.

A further limitation is that we relied on self-reports of proactive behavior. However, our study design addresses several criticisms of self-reports. First, biases such as social 
desirability bias should apply equally to all three measurement occasions and to all behavioral outcomes, enhancing the validity of changes in these ratings. Further, participants were aware that their responses were confidential and had no reason to inflate their ratings. There is evidence that self-ratings of positive work behaviors are only slightly higher than otherratings (Carpenter, Berry \& Houston, 2014). Our randomized control design also helps to alleviate concerns about biases in self-ratings as these would equally apply to all three groups. In addition, previous research has found that self-ratings of proactive work behavior were significantly related to expert ratings (Parker et al., 2006; see also Griffin et al., 2007). Together, these findings provide support for the validity of self-reports of proactive behavior. It is also conceivable that participants increased their self-ratings of proactivity because they expected this to be the outcome of the intervention. However, despite the fact that participants in both interventions were given the same information regarding the intended outcome of the training ("becoming active in making changes"), the interventions had distinct effects. A further point is that there would have been disadvantages to relying on supervisor ratings of proactivity because supervisors do not always notice these behaviors (Wrzesniewski \& Dutton, 2001). Although these arguments support the use of self-reports of proactive behavior, future research should replicate our findings using peer- or supervisor-ratings. Another possible explanation of our findings could be that individuals low in future orientation and high in role overload experienced regression to the mean. If the low future orientation group had relatively high levels of organization member proactivity at the outset of the study, it is possible that the lowered means over time reflect a reversion back to less extreme scores. Similarly, if the high role overload group initially showed relatively low levels of individual task proactivity, increase in these behaviors could reflect a regression to the mean. To test this, we created high and low future orientation and role overload groups, using a median split, and compared the three experimental groups in their initial levels of individual task proactivity and organization member proactivity. There were no significant 
differences between the groups ${ }^{6}$, suggesting that initial differences between individuals high and low in future orientation or role overload are unlikely to account for the findings. 


\section{REFERENCES}

Abdel-Halim, A. A. 1978. Employee affective responses to organizational stress: Moderating effects of job characteristics. Personnel Psychology, 31(3): 561-579.

Association for Talent Development. 2014. State of the industry report. Alexandria, VA: ATD Research.

Atance, C. M., \& O'Neill, D. K. 2001. Episodic future thinking. Current trends in Cognitive Sciences, 5(12): 533-539.

Axtell, C. M., Holman, D. J., Unsworth, K. L., Wall, T. D., \& Waterson, P. E. 2000. Shop floor innovation: Facilitating the suggestion and implementation of ideas. Journal of Occupational and Organizational Psychology, 73(3): 265-285.

Baltes, P. B. 1997. On the incomplete architecture of human ontogeny: Selection, optimization, and compensation as foundation of developmental theory. American Psychologist, 52(4): 366-380.

Bandura, A. 1977. Self-efficacy: Toward a unifying theory of behavioral change. Psychological Review, 84(2): 191-215.

Bandura, A. 1982. Self-efficacy mechanism in human agency. American Psychologist, 37: 122-147.

Bindl, U. K., \& Parker, S. K. 2011. Proactive work behavior: Forward-thinking and changeoriented action in organizations. In S. Zedeck (Ed.), APA handbook of industrial and organizational psychology: 567-598. Washington, DC: American Psychological Association.

Bindl, U. K., Parker, S. K., Totterdell, P., \& Hagger-Johnson, G. 2012. Fuel of the self-starter: How mood relates to proactive goal regulation. Journal of Applied Psychology, 97(1): 134-150.

Boldero, J., \& Francis, J. 2002. Goals, standards, and the self: Reference values serving different functions. Personality and Social Psychology Bulletin, 6(3): 232-241.

Bond, F. W., \& Bunce, D. 2000. Mediators of change in emotion-focused and problem-focused worksite stress management interventions. Journal of Occupational Health Psychology, 5(1): 156-163.

Bunce, D., \& West, M. A. 1996. Stress management and innovation interventions at work. Human Relations, 49(2): 209-232. 
Caplan, R. D., Cobb, S., French, J. R. P., Jr, Harrison, R. V., \& Pinneau, S. R. 1975. Job demands and worker health: Main effects and occupational differences. Washington, DC: U.S. Government Printing Office.

Carpenter, N. C., Berry, C. M., \& Houston, L. 2014. A meta-analytic comparison of self-reported and other-reported organizational citizenship behavior. Journal Of Organizational Behavior, 35(4): 547 574.

Carver, C. S., \& Scheier, M. F. 1982. Control theory: A useful conceptual framework for personalitysocial, clinical, and health psychology. Psychological bulletin, 92(1): 111-135.

Carver, C. S., \& Scheier, M. F. 1998. On the self-regulation of behavior. New York: Cambridge University Press.

Carver, C. S., Sutton, S. K., \& Scheier, M. F. 2000. Action, emotion, and personality: Emerging conceptual integration. Personality and Social Psychology Bulletin, 26(6): 741-751.

Claes, R., \& Ruiz-Quintanilla, S. A. 1998. Influences of early career experiences, occupational group, and national culture on proactive career behavior. Journal of Vocational Behavior, 52: 357-378.

Cook, T. D., \& Campbell, D. J. 1979. Quasi-experimentation: Design and analysis issues for field settings. Boston: Houghton Mifflin Company.

Crant, J. M. 2000. Proactive behavior in organizations. Journal of Management, 26(3): 435-462.

Crossley, C. D., Cooper, C. D., \& Wernsing, T. S. 2013. Making things happen through challenging goals: Leader proactivity, trust, and business-unit performance. Journal of Applied Psychology, 98(3): 540549.

Elliot, A. J. 1999. Approach and avoidance motivation and achievement goals. Educational Psychologist, 34: 169-189.

Elliot, A. J., Sheldon, K. M., \& Church, M. A. 1997. Avoidance personal goals and subjective well-being. Personality and Social Psychology Bulletin, 23(9): 915-927.

Ellis, H. C. 1965. The transfer of learning. New York: Macmillan. 
Fay, D., \& Sonnentag, S. 2002. Rethinking the effects of stressors: A longitudinal study on personal initiative. Journal of Occupational Health Psychology, 7(3): 221-234.

Frese, M., \& Fay, D. 2001. Personal initiative: An active performance concept for work in the 21 st century. Research in Organizational Behavior, 23: 133-187.

Frese, M., \& Zapf, D. 1994. Action as the core of work psychology: A German approach. In H. C. Triandis, M. D. Dunnette and L. M. Hough (Eds.), Handbook of Industrial and Organizational Psychology: 271-340. Palo Alto, CA: Consulting Psychologists Press.

Fried, Y., \& Slowik, L. H. 2004. Enriching goal-setting theory with time: An integrated approach. Academy of Management Review, 29(3): 404-422.

Friedrich, C., Glaub, M., Gramberg, K., \& Frese, M. 2006. Does training improve the business performance of small-scale entrepreneurs? An evaluative study. Industry and Higher Education, 20(2): 75-84.

Fritz, C., \& Sonnentag, S. 2009. Antecedents of day-level proactive behavior: A look at job stressors and positive affect during the workday. Journal of Management, 35(1): 94-111.

Fuller, J. B., \& Marler, L. E. 2009. Change driven by nature: A meta-analytic review of the proactive personality literature. Journal of Vocational Behavior, 75(3): 329-345.

Gilson, L. L., \& Shalley, C. E. 2004. A little creativity goes a long way: An examination of teams' engagement in creative processes. Journal of Management, 30(4): 453-470.

Gollwitzer, P. M. 1990. Action phases and mind-sets. In R. M. Sorrentino and E. T. Higgins (Eds.), Handbook of motivation and cognitioin: Foundations of social behavior. New York: Guildford Press. Gollwitzer, P. M. 1999. Implementation intentions: Strong effects of simple plans. American Psychologist, 54(7): 493-503.

Grant, A. M., \& Ashford, S. J. 2008. The dynamics of proactivity at work: Lessions from feedback-seeking and organizational citizenship behavior research. Research in Organizational Behavior, 28: 3-34.

Grawitch, M. J., Barber, L. K., \& Justice, L. 2010. Rethinking the work-life interface: It's not about balance, it's about resource allocation. Applied Psychology: Health and Well-Being, 2(2): 127-159. 
Griffin, M. A., Neal, A., \& Parker, S. K. 2007. A new model of work role performance: Positive behavior in uncertain and interdependent contexts. Academy of Management Journal, 50(2): 327 - 347.

Griffin, M. A., Parker, S. K., \& Mason, C. M. 2010. Leader vision and the development of adaptive and proactive performance: A longitudinal study. Journal of Applied Psychology, 95(1): 174-182.

Halbesleben, J. R. B., \& Bowler, W. M. 2007. Emotional exhaustion and job performance: The mediating role of motivation. Journal of Applied Psychology, 92(1): 93-106.

Halbesleben, J. R. B., \& Wheeler, A. R. in press. To invest or not? The role of coworker support and trust in daily reciprocal gain spirals of helping behavior. Journal of Management.

Higgins, E. T. 1998. Promotion and prevention: Regulatory focus as a motivational principle. Advances in Experimental Social Psychology, 30: 1-47.

Hobfoll, S. E. 1989. Conservation of resources: A new attempt at conceptualizing stress. American Psychologist, 44(3): 513-524.

Hobfoll, S. E. 2001. The influence of culture, community, and the nested self in the stress process: Advancing conservation of resources theory. Applied Psychology: An International Review, 50(3): 337-370.

Hofmann, D. A., \& Gavin, M. B. 1998. Centering decisions in hierarchical linear models: Implications for research in organizations. Journal of Management, 24(5): 623-641.

Holman, D. J., Axtell, C. M., Sprigg, C. A., Totterdell, P., \& Wall, T. D. 2010. The mediating role of job characteristics in job redesign interventions: A serendipitous quasi-experiment. Journal of Organizational Behavior, 31(1): 84-105.

Hox, J. 2002. Multilevel analysis: Techniques and applications. Mahwah, NJ, US: Lawrence Erlbaum Associates Publishers.

Jackson, S. E., \& Schuler, R. S. 1985. A meta-analysis and conceptual critique of research on role ambiguity and role conflict in work settings. Organizational Behavior and Human Decision Processes, 36(1): 16-78. 
Joireman, J., Kamdar, D., Daniels, D., \& Duell, B. 2006a. Good citizens to the end? It depends: Empathy and concern with future consequences moderate the impact of a short-term time horizon on organizational citizenship behaviors. Journal of Applied Psychology, 91(6): 1307-1320.

Joireman, J., Strathman, A., \& Balliet, D. 2006b. Considering future consequences: An integrative model. In J. Joireman, A. Strathman and D. Balliet (Eds.), Judgments over time: The interplay of thoughts, feelings, and behaviors: 82-99. New York, NY: Oxford University Press.

Kickul, J., \& Gundy, L. K. 2002. Prospecting for strategic advantage: The proactive entrepreneurial personality and small firm innovation. Journal of Small Business Management, 40(2): 85-97.

Klein, H. J. 1989. An integrated control theory model of work motivation. Academy Of Management Review, 14(2): 150-172.

Latack, J. C. 1986. Coping with job stress: Measures and future directions for scale development. Journal of Applied Psychology, 71(3): 377-385.

Le Blanc, P. M., Hox, J. J., Schaufeli, W. B., Taris, T. W., \& Peeters, M. C. W. 2007. Take care! The evaluation of a team-based burnout intervention program for oncology care providers. Journal of Applied Psychology, 92(1): 213-227.

Locke, E. A., \& Latham, G. P. 1990. A theory of goal setting and task performance. Englewood Cliffs, NJ: Prentice-Hall.

Locke, E. A., \& Latham, G. P. 2002. Building a practically useful theory of goal setting and task motivation: A 35-year odyseey. American Psychologist, 57(9): 705-717.

Luthans, F., Avey, J. B., Avolio, B. J., \& Peterson, S. J. 2010. The development and resulting performance impact of positive psychological capital. Human Resource Development Quarterly, 21(1): 41-67.

Michie, S., \& Williams, S. 2003. Reducing work related psychological ill health and sickness absence: A systematic literature review. Occupational and Environmental Medicine, 60(1): 3-9.

Morisano, D., Hirsh, J. B., Peterson, J. B., Pihl, R. O., \& Shore, B. M. 2010. Setting, elaborating, and reflecting on personal goals improves academic performance. Journal of Applied Psychology, 95(2): 255-264. 
Muthén, L., \& Muthén, B. 2012. Mplus user’s guide. Los Angeles, CA: Muthén \& Muthén.

Ng, T. W. H., \& Feldman, D. C. 2012. Employee voice behavior: A meta-analytic test of the conservation of resources framework. Journal of Organizational Behavior, 33(2): 216-234.

Nurmi, J.-E. 1992. Age differences in adult life goals, concerns, and their temporal extension: A life course approach to future-oriented motivation. International Journal of Behavioral Development, 15(4): 487-508.

Oettingen, G. 1999. Free fantasies about the future and the emergence of developmental goals. In J. Brandstädter and R. M. Lerner (Eds.), Action and self-development: Theory and research through the life span: 315-342. Thousand Oaks: Sage.

Oettingen, G. 2000. Expectancy effects on behavior depend on self-regulatory thought. Social Cognition, 18(2): 101-129.

Oettingen, G., Mayer, D., Thorpe, J. S., Janetzke, H., \& Lorenz, S. 2005. Turning fantasies about positive and negative futures into self-improvement goals. Motivation and Emotion, 29(4): 237-267.

Oettingen, G., Mayer, D., Timur Sevincer, A., Stephens, E. J., Pak, H., \& Hagenah, M. 2009. Mental contrasting and goal commitment: The mediating role of energization. Personality and Social Psychology Bulletin, 35(5): 608-622.

Oettingen, G., Pak, H., \& Schnetter, K. 2001. Self-regulation of goal-setting: Turning free fantasies about the future into binding goals. Journal of Personality and Social Psychology, 80(5): 736-753.

Orbell, S., \& Kyriakaki, M. 2008. Temporal framing and persuasion to adopt preventive health behavior: Moderating effects of individual differences in consideration of future consequences on sunscreen use. Health Psychology, 27(6): 770-779.

Orbell, S., Perugini, M., \& Rakow, T. 2004. Individual differences in sensitivity to health communications: Consideration of future consequences. Health Psychology, 23(4): 388-396.

Parker, S. K., Bindl, U. K., \& Strauss, K. 2010. Making things happen: A model of proactive motivation Journal of Management, 36(4): 827-856. 
Parker, S. K., \& Collins, C. G. 2010. Taking stock: Integrating and differentiating multiple proactive behaviors. Journal of Management, 36(3): 633-662.

Parker, S. K., Johnson, A., Collins, C. G., \& Hong, H. 2013. Making the most of structural support: Moderating influence of employees' clarity and negative affect. Academy of Management Journal, 56(3): 867-892.

Parker, S. K., \& Wall, T. D. 1998. Job and work design: Organizing work to promote well- being and effectiveness. San Francisco, CA: Sage.

Parker, S. K., Williams, H. M., \& Turner, N. 2006. Modeling the antecedents of proactive behavior at work. Journal of Applied Psychology, 91(3): 636-652.

Pennington, G. L., \& Roese, N. J. 2003. Regulatory focus and temporal distance. Journal of Experimental Social Psychology, 39: 563-576.

Petrocelli, J. V. 2003. Factor validation of the consideration of future consequences scale: Evidence for a short version. Journal of Social Psychology, 143(4): 405-413.

Raabe, B., Frese, M., \& Beehr, T. A. 2007. Action regulation theory and career self-management. Journal of Vocational Behavior, 70: 297-311.

Raudenbush, S. W. 1989. The analysis of longitudinal, multilevel data. International Journal of Educational Research, 13(7): 721-740.

Reivich, K. J., Seligman, M. E. P., \& McBride, S. 2011. Master resilience training in the U.S. Army. American Psychologist, 66(1): 25-34.

Saks, A. M., Uggerslev, K. L., \& Fassina, N. E. 2007. Socialization tactics and newcomer adjustment: A meta-analytic review and test of a model. Journal of Vocational Behavior, 70(3): 413-446.

Schriber, J. B., \& Gutek, B. A. 1987. Some time dimensions of work: Measurement of an underlying aspect of organization culture. Journal of Applied Psychology, 72(4): 642-650.

Schyns, B., Tymon, A., Kiefer, T., \& Kerschreiter, R. 2013. New ways to leadership development: A picture paints a thousand words. Management Learning, 44(1): 11-24. 
Searle, B. J. 2008. Does Personal Initiative training work as a stress management intervention? Journal of Occupational Health Psychology, 13(3): 259-270.

Seligman, M. E. P. 2006. Learned optimism: How to change your mind and your life. New York, NY: Free Press.

Seligman, M. E. P., \& Schulman, P. 1986. Explanatory style as a predictor of productivity and quitting among life insurance sales agents. Journal of Personality and Social Psychology, 50(4): 832-838.

Shadish, W. R. 2002. Revisiting field experimentation: Field notes for the future. Psychological Methods, 7(1): 3-18.

Shadish, W. R., Cook, T. D., \& Campbell, D. T. 2002. Experimental and quasi-experimental designs for generalized causal inference. Boston: Houghton Mifflin Company.

Sheldon, K. M., \& Elliot, A. J. 1999. Goal striving, need satisfaction, and longitudinal well-being: The selfconcordance model. Journal of Personality and Social Psychology, 76(3): 482-497.

Snijders, T. 1996. Analysis of longitudinal data using the hierarchical linear model. Quality \& Quantity, 30(4): 405-426.

Snyder, C. R. 2000. Handbook of hope. San Diego: Academic Press.

Stock, J., \& Cervone, D. 1990. Proximal goal-setting and self-regulatory processes. Cognitive Therapy and Research, 14: 483-498.

Strathman, A., Gleicher, F., Boninger, D. S., \& Edwards, C. S. 1994. The consideration of future consequences: Weighing immediate and distant outcomes of behavior. Journal of Personality and Social Psychology, 66(4): 742-752.

Strauss, K., Griffin, M. A., \& Parker, S. K. 2012. Future work selves: How salient hoped-for identities motivate proactive career behaviors. Journal of Applied Psychology, 97(3): 580-598.

Taylor, P. J., Russ-Eft, D. F., \& Chan, D. W. L. 2005. A meta-analytic review of behavior modeling training. Journal of Applied Psychology, 90(4): 692-709. 
Thomas, J. P., Whitman, D. S., \& Viswesvaran, C. 2010. Employee proactivity in organizations: A comparative meta-analysis of emergent proactive constructs. Journal of Occupational and Organizational Psychology, 83(2): 275-300.

Thompson, J. A. 2005. Proactive personality and job performance: A social capital perspective. Journal of Applied Psychology, 90(5): 1011-1017.

Toepoel, V. 2010. Is consideration of future consequences a changeable construct? Personality and Individual Differences, 48(8): 951-956.

Warr, P. B., Allen, C., \& Birdi, K. 1999. Predicting three levels of training outcome. Journal of Occupational and Organizational Psychology, 72(3): 351-375.

Weiner, B. 1985. An attributional theory of achievement motivation and emotion. Psychological Review, 92(4): 548-573.

Wexley, K. N., \& Baldwin, T. T. 1986. Posttraining strategies for facilitating positive transfer: An empirical exploration. Academy of Management Journal, 29(3): 503-520.

Wrzesniewski, A., \& Dutton, J. E. 2001. Crafting a job: Revisioning employees as active crafters of their work. Academy Of Management Review, 26(2): 179-201. 


\section{TABLES}

Table 1

Overview of interventions

\begin{tabular}{|c|c|}
\hline $\begin{array}{l}\text { Problem-focused intervention } \\
\text { (based on Bond \& Bunce, 2000) }\end{array}$ & $\begin{array}{l}\text { Vision-focused intervention } \\
\text { (based on Strauss et al., 2012) }\end{array}$ \\
\hline $\begin{array}{l}\text { - Recognizing resource depletion } \\
\text { (symptoms, effects, and common causes) }\end{array}$ & $\begin{array}{l}\text { - Envisioning the future work self (Strauss } \\
\text { et al., 2012) }\end{array}$ \\
\hline - Identifying changeable threats to & - Identifying discrepancies between current \\
\hline resources - discrepancies between status & self and future work self - discrepancies \\
\hline quo and current resource requirements & between status quo and future resource \\
\hline $\begin{array}{l}\text { - Setting goals to address changeable } \\
\text { threats }\end{array}$ & $\begin{array}{l}\text { requirements } \\
\text { - Setting goals to build future resources }\end{array}$ \\
\hline
\end{tabular}

- Pathways training - Identification of potential obstacles and ways of overcoming them; group exercises to facilitate generation of alternative plans in the face of obstacles (Luthans, Avey, Avolio \& Peterson, 2010; Snyder, 2000)

- Stepping - breaking goals down into specific action plans (Snyder, 2000)

- Goal commitment and implementation plans (Gollwitzer, 1990) - specification of how and when goals will be achieved ; publicly sharing goals to solidify personal commitment

- Persistence - reflection on successes and further pathways training in the follow-up workshop 
Table 2

Means and Standard Deviation Scores of Study Variables

\begin{tabular}{|c|c|c|c|c|c|c|c|}
\hline & & \multicolumn{2}{|c|}{$\begin{array}{l}\text { Problem-focused } \\
\text { intervention }\end{array}$} & \multicolumn{2}{|c|}{$\begin{array}{l}\text { Vision-focused } \\
\text { intervention }\end{array}$} & \multicolumn{2}{|c|}{$\begin{array}{l}\text { No treatment } \\
\text { control group }\end{array}$} \\
\hline & & Mean & SD & Mean & SD & Mean & SD \\
\hline 1. & Age (in years) & 38.69 & 9.52 & 40.23 & 8.41 & 39.33 & 8.74 \\
\hline 2. & Gender & 1.46 & 0.51 & 1.58 & 0.50 & 1.58 & 0.50 \\
\hline 3. & Tenure (in years) & 11.20 & 10.70 & 11.60 & 8.51 & 10.39 & 7.45 \\
\hline 4. & Role overload T1 & 3.07 & 0.77 & 3.17 & 1.15 & 3.16 & 1.03 \\
\hline 5. & Future orientation $\mathrm{T} 1$ & 3.38 & 0.56 & 3.45 & 0.70 & 3.51 & 0.67 \\
\hline 6. & Individual task proactivity $\mathrm{T} 1$ & 2.65 & 1.00 & 2.87 & 1.04 & 2.94 & 1.25 \\
\hline 7. & Individual task proactivity $\mathrm{T} 2$ & 2.59 & 1.11 & 2.58 & 1.21 & 2.63 & 1.08 \\
\hline 8. & Individual task proactivity $\mathrm{T} 3$ & 2.85 & 1.16 & 2.53 & 1.19 & 2.69 & 1.06 \\
\hline 9. & Proactive skill development T1 & 2.35 & 1.12 & 2.65 & 1.03 & 2.72 & 1.16 \\
\hline 10. & Proactive skill development T2 & 2.41 & 1.17 & 2.59 & 1.10 & 2.75 & 1.18 \\
\hline 11. & Proactive skill development T3 & 2.55 & 1.34 & 2.42 & 1.21 & 2.53 & 1.08 \\
\hline 12. & $\begin{array}{l}\text { Organization member } \\
\text { proactivity } \mathrm{T} 1\end{array}$ & 2.00 & 0.91 & 2.33 & 1.17 & 2.15 & 1.21 \\
\hline 13. & $\begin{array}{l}\text { Organization member } \\
\text { proactivity } \mathrm{T} 2\end{array}$ & 2.05 & 1.03 & 2.28 & 1.14 & 2.10 & 1.23 \\
\hline 14. & $\begin{array}{l}\text { Organization member } \\
\text { proactivity } \mathrm{T} 3\end{array}$ & 1.98 & 1.10 & 2.22 & 1.36 & 2.03 & 1.06 \\
\hline
\end{tabular}

Note $. \mathrm{SD}=$ Standard deviation; gender was coded with $1=$ male, $2=$ female 
Table 3

Intercorrelations of Study Variables

$\begin{array}{llllllllllllll}1 & 2 & 3 & 4 & 5 & 6 & 7 & 8 & 9 & 10 & 11 & 12 & 13 & 14\end{array}$

\begin{tabular}{|c|c|c|c|c|c|c|c|c|c|c|c|c|c|}
\hline 2. Gender & -.04 & & & & & & & & & & & & \\
\hline 3. Tenure (in years) & $.63^{* * * *}$ & -.06 & & & & & & & & & & & \\
\hline 4. Role overload $\mathrm{T} 1$ & -.18 & .04 & -.02 & $(.86)$ & & & & & & & & & \\
\hline 5. Future orientation $\mathrm{T} 1$ & -.09 & -.03 & .02 & $.23^{*}$ & $(.68)$ & & & & & & & & \\
\hline 6. Individual task proactivity $\mathrm{T} 1$ & .00 & .07 & .15 & -.06 & $.24^{*}$ & $(.91)$ & & & & & & & \\
\hline 7. Individual task proactivity $\mathrm{T} 2$ & .06 & .10 & .15 & .06 & .19 & $.56^{* * *}$ & $(.93)$ & & & & & & \\
\hline 8. Individual task proactivity $\mathrm{T} 3$ & .03 & -.12 & .22 & .12 & $.28^{*}$ & $.33^{* *}$ & $.59^{* * *}$ & $(.93)$ & & & & & \\
\hline 9. Proactive skill development $\mathrm{T} 1$ & -.13 & .01 & .06 & .13 & $.25^{*}$ & $.47^{* * *}$ & $.44^{* * *}$ & $.37^{* *}$ & $(.91)$ & & & & \\
\hline 10. Proactive skill development T2 & -.09 & .13 & .01 & .13 & $.23^{*}$ & $.42^{* * * *}$ & $.54^{* * *}$ & $.35^{* *}$ & $.53^{* * * *}$ & $(.94)$ & & & \\
\hline 11. Proactive skill development T3 & -.04 & -.16 & .21 & .04 & $.25^{*}$ & $.38^{* * * *}$ & $.44^{* * * *}$ & $.68^{* *}$ & $.46^{* * *}$ & $.45^{* * *}$ & $(.94)$ & & \\
\hline $\begin{array}{l}\text { 12. Organization member } \\
\text { proactivity } \mathrm{T} 1\end{array}$ & .08 & .01 & .12 & .05 & .19 & $.44^{* * *}$ & $.41^{* * *}$ & $.27^{*}$ & $.30^{* * *}$ & $.32^{* *}$ & $.31^{* *}$ & $(.87)$ & \\
\hline $\begin{array}{l}\text { 13. Organization member } \\
\text { proactivity } \mathrm{T} 2\end{array}$ & .12 & -.07 & .06 & -.05 & $.26^{*}$ & $.36^{* * *}$ & $.35^{* * * *}$ & $.29^{*}$ & .20 & $.28^{* *}$ & $.34^{* *}$ & $.49^{* * *}$ & (.93) \\
\hline $\begin{array}{l}\text { 14. Organization member } \\
\text { proactivity } \mathrm{T} 3\end{array}$ & .10 & -.02 & .21 & .07 & $.33^{* *}$ & .15 & $.44^{* * * *}$ & $.47^{* *}$ & .20 & $.24^{*}$ & $.34^{* *}$ & $.50^{* * *}$ & $.54^{* * *}$ \\
\hline
\end{tabular}

Note. $\mathrm{N}=70-100$; Cronbach alpha reliabilities are shown on the diagonal in parentheses ${ }^{*} p<.05$

${ }^{* *} p<.01$

**** $p<.001$ 
Table 4

Multilevel Regression for Time by Intervention Effects, Moderated by Role Overload, Predicting Individual Task proactivity

\begin{tabular}{|c|c|c|c|}
\hline \multirow[b]{2}{*}{ Variable } & \multicolumn{3}{|c|}{ Individual task proactivity } \\
\hline & $\mathrm{B}$ & SE & $\mathrm{t}$ \\
\hline Intercept & $2.73^{* * * *}$ & 0.18 & 15.16 \\
\hline Age & -0.01 & 0.02 & -0.72 \\
\hline Gender & -0.01 & 0.19 & -0.06 \\
\hline Tenure & $0.03^{*}$ & 0.02 & 2.17 \\
\hline Time A (Time 1 vs. Time 2) & 0.21 & 0.18 & 1.17 \\
\hline Time B (Time 2 vs. Time 3 ) & -0.04 & 0.19 & -0.20 \\
\hline Problem-focused intervention (compared to control) & -0.30 & 0.30 & -1.00 \\
\hline Vision-focused intervention (compared to control) & -0.10 & 0.29 & -0.33 \\
\hline Role overload & 0.10 & 0.18 & 0.56 \\
\hline Role overload x Time A & -0.13 & 0.17 & -0.76 \\
\hline Role overload x Time B & -0.19 & 0.20 & -0.98 \\
\hline Problem-focused intervention $\mathrm{x}$ Time A & -0.04 & 0.30 & -0.15 \\
\hline Problem-focused intervention $\mathrm{x}$ Time $\mathrm{B}$ & 0.44 & 0.32 & 1.40 \\
\hline Vision-focused intervention $\mathrm{x}$ Time A & 0.08 & 0.29 & 0.29 \\
\hline Vision-focused intervention $\mathrm{x}$ Time $\mathrm{B}$ & 0.07 & 0.31 & 0.24 \\
\hline Problem-focused intervention x Role overload & $-0.82^{*}$ & 0.39 & -2.09 \\
\hline Vision-focused intervention $\mathrm{x}$ Role overload & 0.33 & 0.28 & 1.20 \\
\hline Problem-focused intervention x Time A x Role overload & 0.26 & 0.38 & 0.69 \\
\hline Vision-focused intervention $\mathrm{x}$ Time A $\mathrm{x}$ Role overload & -0.09 & 0.27 & -0.33 \\
\hline Problem-focused intervention x Time B x Role overload & $0.87^{*}$ & 0.40 & 2.20 \\
\hline Vision-focused intervention $\mathrm{x}$ Time $\mathrm{B} \times$ Role overload & 0.20 & 0.29 & 0.68 \\
\hline
\end{tabular}

Note. $\mathrm{N}=86$;

${ }^{*} p<.05$

${ }_{* * *}^{* *} p<.01$

${ }^{* * * *} p<.001$ 
Table 5

Multilevel Regression for Time by Intervention Effects, Moderated by Future Orientation, Predicting Organization Member Proactivity and Proactive Skill Development

\begin{tabular}{|c|c|c|c|c|c|c|}
\hline \multirow[b]{2}{*}{ Variable } & \multicolumn{3}{|c|}{ Organization Member Proactivity } & \multicolumn{3}{|c|}{ Proactive Skill Development } \\
\hline & $\mathrm{B}$ & $\mathrm{SE}$ & $\mathrm{t}$ & $\mathrm{B}$ & $\mathrm{SE}$ & $\mathrm{t}$ \\
\hline Intercept & $2.01^{* * *}$ & 0.18 & 11.07 & $2.76^{* * *}$ & 0.20 & 13.92 \\
\hline Age & 0.02 & 0.01 & 1.05 & -0.02 & 0.01 & -1.57 \\
\hline Gender & 0.01 & 0.20 & 0.04 & 0.01 & 0.20 & 0.04 \\
\hline Tenure & 0.00 & 0.01 & 0.33 & 0.02 & 0.01 & 1.65 \\
\hline Time A (Time 1 vs. Time 2) & 0.13 & 0.17 & 0.78 & 0.01 & 0.19 & 0.07 \\
\hline Time B (Time 2 vs. Time 3 ) & 0.08 & 0.20 & 0.41 & -0.26 & 0.23 & -1.16 \\
\hline $\begin{array}{l}\text { Problem-focused intervention } \\
\text { (compared to control) }\end{array}$ & -0.05 & 0.29 & -0.16 & -0.23 & 0.31 & -0.72 \\
\hline $\begin{array}{l}\text { Vision-focused intervention } \\
\text { (compared to control) }\end{array}$ & 0.32 & 0.29 & 1.12 & -0.31 & 0.32 & -0.96 \\
\hline Future orientation & 0.52 & 0.32 & 1.64 & 0.63 & 0.35 & 1.83 \\
\hline Future orientation $\mathrm{x}$ Time A & 0.13 & 0.30 & 0.42 & -0.20 & 0.33 & -0.60 \\
\hline Future orientation $\mathrm{x}$ Time $\mathrm{B}$ & -0.15 & 0.35 & -0.44 & 0.03 & 0.40 & 0.08 \\
\hline $\begin{array}{l}\text { Problem-focused intervention } \mathrm{x} \\
\text { Time A }\end{array}$ & -0.07 & 0.28 & -0.25 & 0.03 & 0.30 & 0.09 \\
\hline $\begin{array}{l}\text { Problem-focused intervention } \mathrm{x} \\
\text { Time B }\end{array}$ & -0.11 & 0.31 & -0.35 & 0.16 & 0.36 & 0.44 \\
\hline $\begin{array}{l}\text { Vision-focused intervention } \mathrm{x} \\
\text { Time A }\end{array}$ & -0.05 & 0.27 & -0.18 & -0.07 & 0.30 & -0.22 \\
\hline $\begin{array}{l}\text { Vision-focused intervention } \mathrm{x} \\
\text { Time B }\end{array}$ & -0.17 & 0.31 & -0.54 & 0.34 & 0.36 & 0.94 \\
\hline $\begin{array}{l}\text { Problem-focused intervention } \mathrm{x} \\
\text { Future orientation }\end{array}$ & -0.25 & 0.51 & -0.49 & -0.12 & 0.51 & -0.23 \\
\hline $\begin{array}{l}\text { Vision-focused intervention } \mathrm{x} \\
\text { Future orientation }\end{array}$ & 0.25 & 0.47 & 0.53 & -0.92 & 0.56 & -1.65 \\
\hline $\begin{array}{l}\text { Problem-focused intervention x } \\
\text { Time A x Future orientation }\end{array}$ & -0.39 & 0.48 & -0.81 & 0.23 & 0.49 & 0.48 \\
\hline $\begin{array}{l}\text { Vision-focused intervention } x \\
\text { Time A x Future Orientation }\end{array}$ & $-1.24^{* *}$ & 0.44 & -2.80 & 0.65 & 0.53 & 1.22 \\
\hline $\begin{array}{l}\text { Problem-focused intervention x } \\
\text { Time B x Future orientation }\end{array}$ & 0.29 & 0.54 & 0.53 & 0.42 & 0.58 & 0.72 \\
\hline $\begin{array}{l}\text { Vision-focused intervention } \mathrm{x} \\
\text { Time B x Future orientation }\end{array}$ & 0.52 & 0.50 & 1.02 & 0.01 & 0.62 & 0.01 \\
\hline
\end{tabular}

Note. $\mathrm{N}=86 ;{ }^{*} p<.05,{ }^{* *} p<.01,{ }^{* * *} p<.001$ 


\section{FIGURES}

Figure 1

Conceptual Model
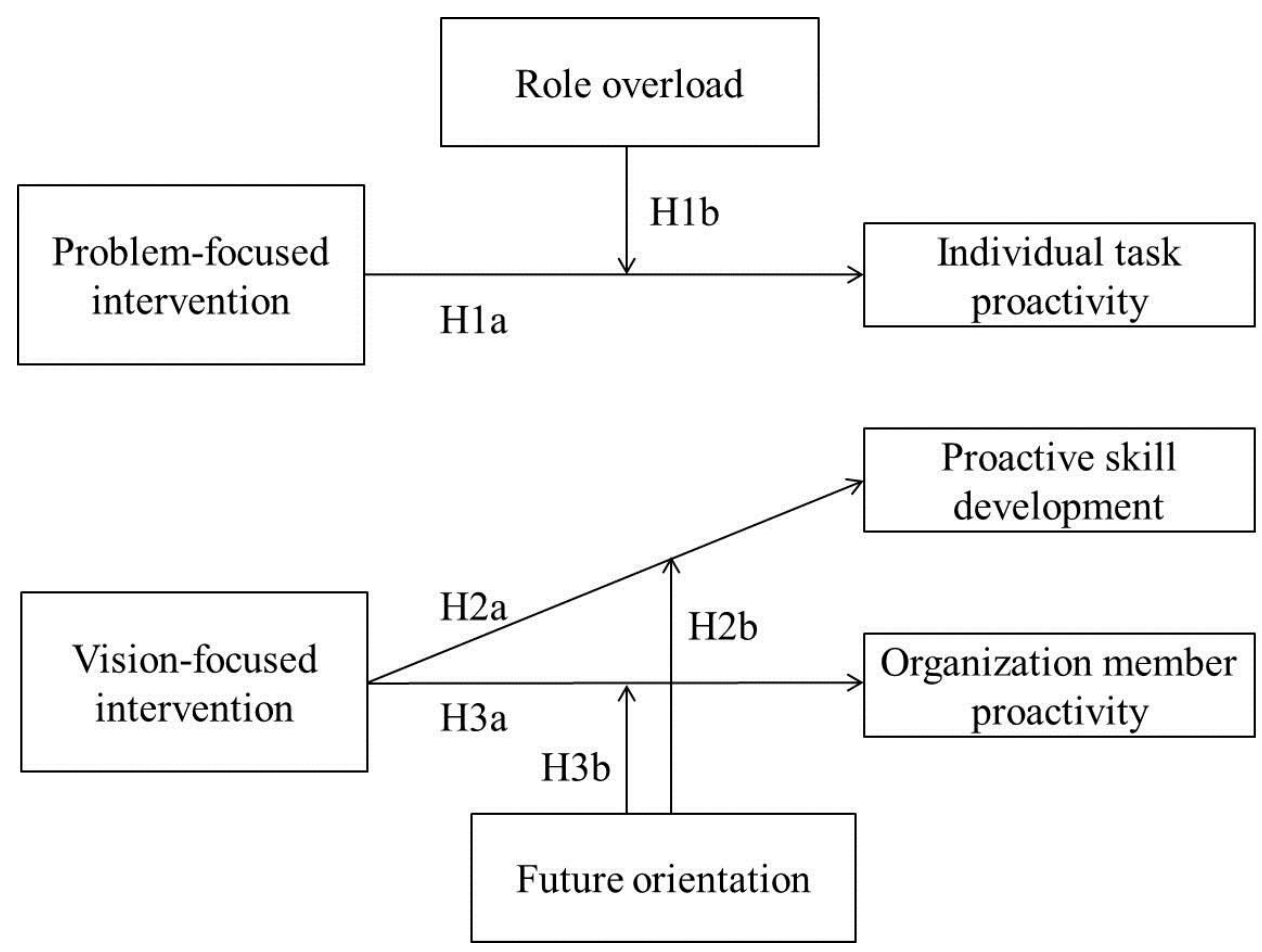
Figure 2

Three-way Interaction of Role Overload, Problem-focused Intervention, and Time on Individual Task Proactivity

\section{Low Role Overload}

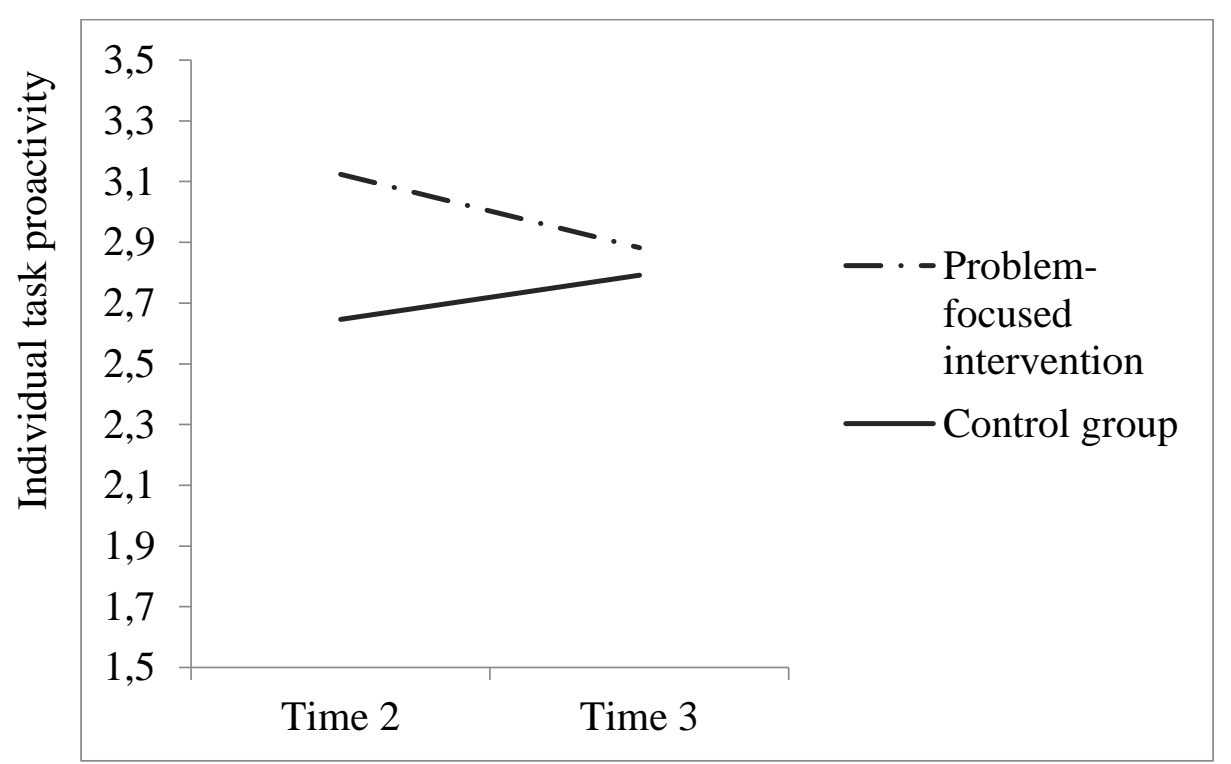

\section{High Role Overload}

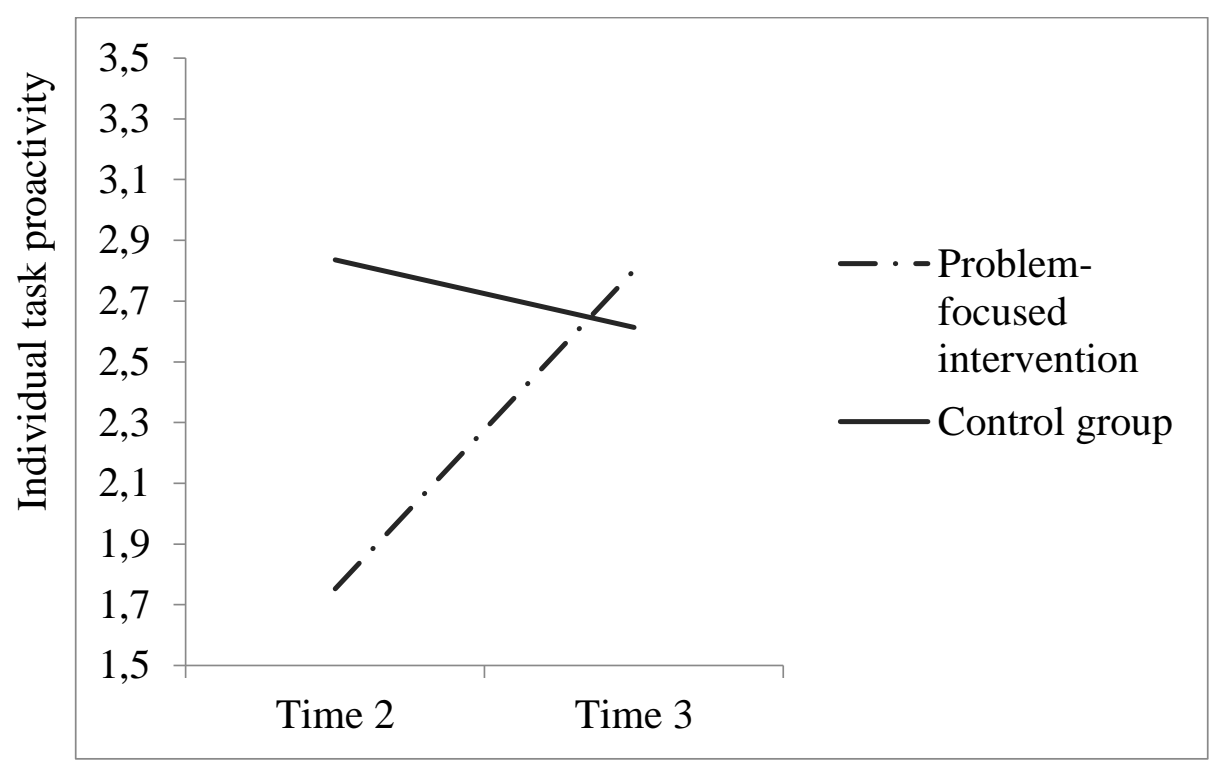


Figure 3

Three-way Interaction of Future orientation, Vision-focused intervention, and Time on Organization Member Proactivity

\section{Low future orientation}

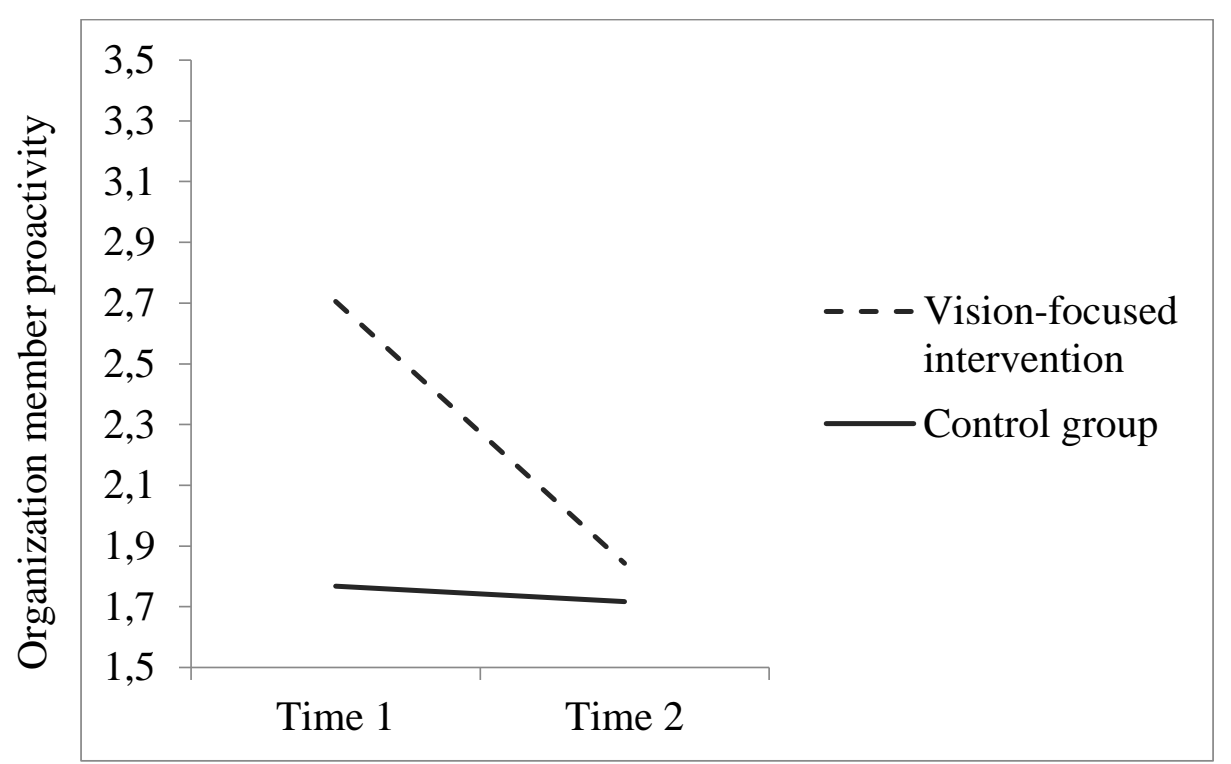

\section{High future orientation}

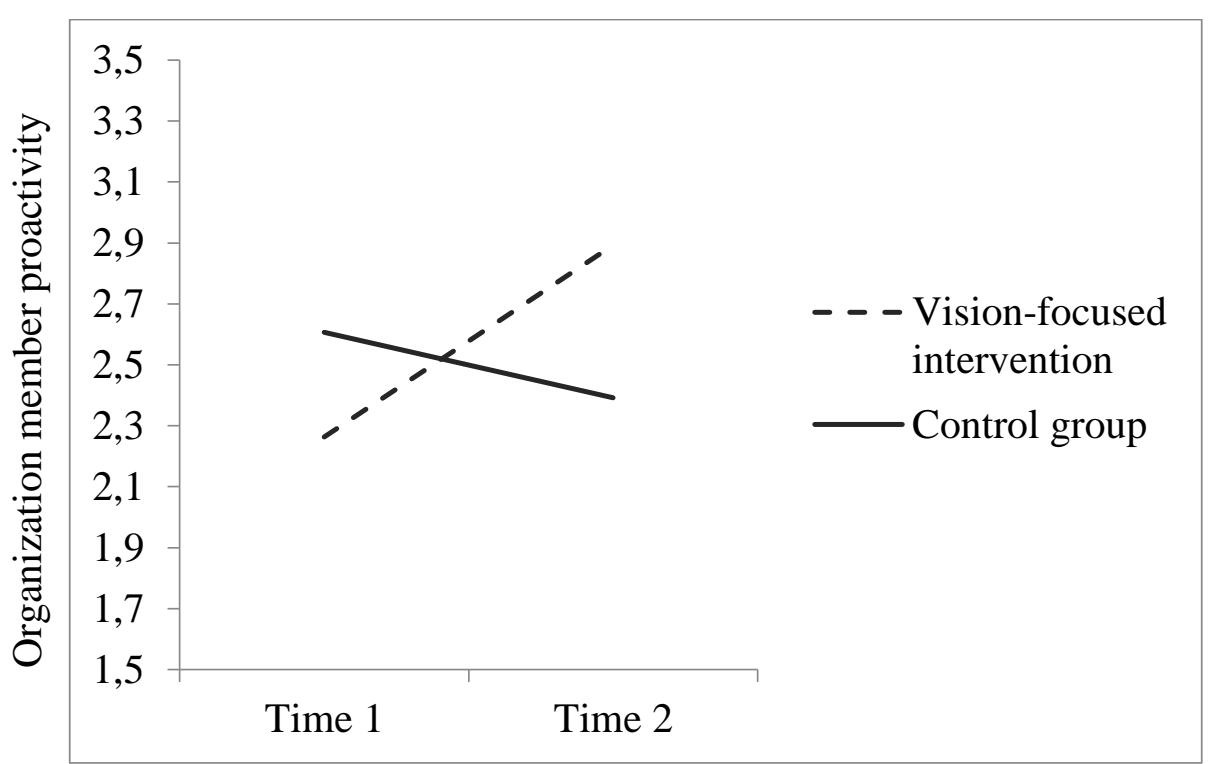




\section{FOOTNOTES}

${ }^{1}$ Age: $\mathrm{F}(2,110)=0.12, p=.88$; organizational tenure: $\mathrm{F}(2,99)=0.13, p=.88$; gender: $\mathrm{F}(2,108)=0.36, p=.70$

${ }^{2}$ Future orientation: $\mathrm{F}(2,108)=0.70, p=.50$; role overload: $\mathrm{F}(2,108)=0.08, p=.92$; individual task proactivity: $\mathrm{F}(2,108)=0.56, p=.58$; proactive skill development $: \mathrm{F}(2,107)=$ $1.39, p=.25$; organization member proactivity: $\mathrm{F}(2,108)=0.62, p=.54$

${ }^{3} \mathrm{~T} 2$ : future orientation: $t(109)=0.74, p=.46$; role overload: $t(109)=-0.23, p=.82$; individual task proactivity: $t(109)=-1.71, p=.09$; proactive skill development: $t(108)=-$ $0.61, p=.55$; organization member proactivity: $t(109)=-1.23, p=.26$; T3: future orientation: $t(95)=-1.30, p=.20$; role overload: $t(95)=-0.48, p=.63$; individual task proactivity: $t(95)=$ $1.25, p=.22$; proactive skill development: $t(95)=-0.71, p=.48$; organization member proactivity: $t(95)=1.05, p=.30$

${ }^{4}$ Participants indicated how long they had been working in their current role. For $\mathrm{N}=11$, tenure in current role changed between time points, indicating a change in job role.

${ }^{5}$ Three participants in the problem-focused intervention and six participants in the vision-focused intervention took part only in the first workshop. Because of understaffing, participants could not be released from duty to take part in the workshop. Out of these, five responded to the third survey. Excluding these participants from our analyses did not change the pattern of findings. We thus included their responses.

${ }^{6}$ Low future orientation: individual task proactivity: $\mathrm{F}(2,42)=0.03, p=.97$; organization member proactivity: $\mathrm{F}(2,42)=2.87, p=.07$; high future orientation: task proactivity: $\mathrm{F}(2,56)=0.70, p=.50$; organization member proactivity: $\mathrm{F}(2,56)=0.37, p=.69$; low role overload: individual task proactivity: $\mathrm{F}(2,43)=0.21, p=.82$; organization member proactivity: $\mathrm{F}(2,43)=1.10, p=.34$; high role overload: task proactivity: $\mathrm{F}(2,55)=1.22, p=$ .30 ; organization member proactivity: $\mathrm{F}(2,55)=1.80, p=.18$. 